\title{
Influence of cirrus cloud radiative forcing on climate and climate sensitivity in a general circulation model
}

\author{
Ulrike Lohmann and Erich Roeckner \\ Max-Planck-Institut für Meteorologie, Hamburg, Germany
}

\begin{abstract}
Six numerical experiments have been performed with a general circulation model (GCM) to study the influence of high-level cirrus clouds and global sea surface temperature (SST) perturbations on climate and climate sensitivity. The GCM used in this investigation is the third-generation ECHAM3 model developed jointly by the Max Planck Institute for Meteorology and the University of Hamburg. It is shown that the model is able to reproduce many features of the observed cloud radiative forcing with considerable skill, such as the annual mean distribution, the response to seasonal forcing, and the response to observed SST variations in the equatorial Pacific. In addition to a reference experiment where the cirrus emissivity is computed as a function of the cloud water content, two sensitivity experiments have been performed in which the cirrus emissivity is either set to zero everywhere above $400 \mathrm{hPa}$ ("transparent cirrus") or set to 1 ("black cirrus"). These three experiments are repeated identically, except for prescribing a globally uniform SST warming of $4 \mathrm{~K}$. Similar to earlier GCM studies, the changed cloud radiative heating within the troposphere has a profound impact on the model climate. Since the initial radiative forcing introduced by the changed cirrus emissivity is much smaller than the convective or dynamical response, we conclude that the tropical circulation, in particular, is maintained through a positive feedback loop involving cirrus radiative heating, deep cumulus convection, and moisture supply through the large-scale dynamics. Since this interaction has been identified in at least two other GCMs employing different cumulus parameterizations, it does not crucially depend on the respective closure assumption. Moreover, the radiative-convective-dynamical coupling in the tropics is relevant also in the global warming experiment through the increase of cloud water and hence cirrus radiative heating in the warmer atmosphere. It is shown that the spin-up of the Walker circulation in both the global warming and the increased cirrus emissivity experiments is a result of a selection process which enhances the diabatic heat source through asymmetries of the circulation itself, and the extra differential heating feeds back positively on the circulation. It is also shown that cirrus clouds have a significant influence on the global climate sensitivity of the model. In the climate change experiment with the standard model, the climate sensitivity is $20 \%$ higher than in a clear-sky reference atmosphere because the increase of cirrus emissivity in the warmer atmosphere contributes substantially to the overall positive cloud feedback. In the transparent cirrus model the cloud feedback is negative, and the global sensitivity is reduced by $20 \%$ as compared to a clear-sky reference atmosphere.
\end{abstract}

\section{Introduction}

There is growing observational and modeling evidence that cloud radiative processes play a major role in regulating global climate and climate sensitivity. According to analyses of satellite measurements taken during the Earth Radiation Budget Experiment (ERBE), the net radiative effect of clouds is to cool the planet by approximately $20 \mathrm{~W} / \mathrm{m}^{2}$ in the global annual mean because the cloud albedo effect is larger than the cloud greenhouse effect [Hartmann, 1993]. In the tropics both components (often referred to as shortwave and longwave cloud radiative forcing, respectively [e.g. Ramanathan et al, 1989]) are large and nearly equal in magnitude, so that the net effect is close to zero. Since net cloud radiative cooling prevails in higher latitudes, the present cloud distribution enhances the Copyright 1995 by the American Geophysical Union.

Paper number 95JD01383.

0148-0227/95/95JD-01383\$05.00 equator-to-pole gradient of net radiative heating relative to a clear-sky atmosphere, and this excess heating has to be balanced by an increase of the atmospheric and/or oceanic meridional heat transport.

Observational data of the net cloud radiative forcing within the atmosphere or at the surface are not yet available for isolating the atmospheric and oceanic contributions to the cloud-induced heat transport. Modeling studies indicate, however, that the cloud albedo effect is mostly felt at the Earth's surface, while the cloud greenhouse effect, at least in the tropics, is largely confined to the atmosphere [Slingo and Slingo, 1988; Harshvardhan et al., 1989]. According to these studies the sign and the magnitude of the atmospheric longwave cloud radiative forcing depends crucially on parameters such as cloud top temperature, cloud optical depth, and water vapor concentration beneath cloud base. Tropical cirrus, for example, is warming the atmosphere because the absorption of infrared radiation emitted from the ground surface is larger 
than the emission to space from the extremely cold cloud tops. The surface warming, on the other hand, is small because most of the downwelling infrared radiation is absorbed by water vapor between the surface and the cloud base. At higher latitudes where water vapor is less abundant, a substantial fraction of the downwelling radiation emitted from cloud base reaches the ground. Moreover, because of the relatively high cloud top temperature (relative to the surface temperature) and the large optical depth of low-level stratus and stratocumulus prevailing in middle and high latitudes, the cloud layer is cooled radiatively, so that the atmospheric longwave cloud radiative forcing outside the tropics is negative. In summary, according to these modeling studies the net cloud radiative effect on the troposphere is a warming in low latitudes and a cooling in high latitudes. In terms of global energetics the cloud-induced increase of the meridional diabatic heating gradient within the troposphere contributes to the generation of zonal available potential energy and helps to maintain the general circulation against frictional dissipation. The interplay between cloud radiative processes in the atmosphere, the hydrological cycle and the general circulation has been investigated by means of GCM experiments with and without the atmospheric component of the longwave cloud radiative forcing, respectively [Slingo and Slingo, 1988; Randall et al., 1989; Sherwood et al., 1994]. The main conclusion from these studies is that the infrared cloud radiative warming of the atmosphere, although considerably smaller than the latent heat release in convective clouds, has a crucial influence on the atmospheric circulation through a positive feedback loop involving cloud radiative heating of the atmosphere, moisture supply by the large-scale circulation, and latent heat release in convective cloud systems.

In this study we investigate to what extent these interactions are relevant for understanding the dynamic response to global warming realized by an increase of sea surface temperature (SST) by uniformly 4K, in the spirit of the investigation by Cess et al. [1990]. In addition to a reference experiment and a global warming experiment, we performed two sensitivity experiments in which the cirrus cloud emissivity was either set to 0 or 1 , and the respective responses are used to interpret the results of the global warming experiment.

In section 2 we discuss the basic features of the model used for the present study together with the design of the sensitivity experiments. It is shown in section 3 that the model is able to faithfully reproduce many aspects of the observed cloud radiative forcing such as its annual cycle and SST-induced interannual variations in the tropics. The results of the sensitivity experiments are presented in section 4 , with emphasis on the zonally asymmetric part of the circulation, and the impact of cirrus cloud optical properties on climate sensitivity is discussed in section 5. A summary of the basic results concludes this paper (section 6).

\section{Model and Experiments}

The model used in this investigation is the third-generation model ECHAM3 developed jointly at the Max Planck Institute for Meteorology and the University of Hamburg [Roeckner et al., 1992]. The dynamics and part of the model physics have been adopted from the European Center for Medium-Range Weather Forecasts model. Prognostic variables are vorticity, divergence, temperature, logarithm of surface pressure, and the mass mixing ratios of water vapor and cloud water (liquid and ice phase together), respectively. The model equations are solved on 19 vertical levels in a hybrid pressure-sigma system by using the spectral transform method with triangular truncation at wavenumber 21 (T21). Nonlinear terms and physical processes, however, are evaluated at grid points of a "Gaussian grid" providing a nominal resolution of $5.625^{\circ}$ in latitude and longitude. Unlike the operational ECHAM3 model, we use a semi-Lagrangian technique [Rasch and Williamson, 1990] for computing the horizontal and vertical advection of positive definite quantities such as water vapor and cloud water. A second-order horizontal diffusion scheme is applied to vorticity, divergence, and temperature. The diffusion is limited, however, to the high-wavenumber end of the resolved spectrum, and no diffusion is applied to those variables that are treated with the semi-Lagrangian technique, namely, water vapor and cloud water. Otherwise, the model physics remains unchanged.

The radiation scheme is based on a two-stream approximation of the radiative transfer equations with six spectral intervals in the terrestrial infrared and four in the solar part of the spectrum [Hense et al., 1982]. Gaseous absorption due to water vapor, carbon dioxide, and ozone is taken into account as well as scattering and absorption due to prescribed aerosol and model-generated clouds. The cloud optical properties are parameterized in terms of the cloud water content [Stephens, 1978]. The cloud water content is obtained from the respective budget equation, including sources and sinks due to condensation, evaporation, and precipitation formation by coalescence of cloud droplets and sedimentation of ice crystals [Sundqvist, 1978; Roeckner et al., 1991]. The phase separation in clouds is parameterized in terms of ambient temperature on the basis of empirical data [Matveev, 1984]. Subgrid scale condensation and cloud formation is taken into account by specifying appropriate thresholds of relative humidity depending on height and convective activity [Xu and Krueger, 1991]. The convection scheme comprises the effect of deep, shallow, and midlevel convection on the budgets of heat, water vapor, and momentum [Tiedtke, 1989]. Cumulus clouds are represented by a bulk model including the effect of entrainment and detrainment on the updraft and downdraft convective mass fluxes. The turbulent transfer of momentum, heat, water vapor, and cloud water is based upon the Monin-Obukhov similarity theory for the surface layer and the eddy diffusivity approach above the surface layer [Louis, 1979]. The drag and heat transfer coefficients depend on roughness length and Richardson number, and the eddy diffusion coefficients depend on wind shear, mixing length, and Richardson number which is formulated in terms of cloud-conservative variables taking into account the effect of condensation on stability [Brinkop, 1991]. The soil model comprises the budgets of heat and water in the soil, the snow pack over land, and the heat budget of permanent land ice and sea ice. The heat transfer equation is solved in a five-layer model assuming vanishing heat flux at the bottom. Vegetation effects such as the interception of rain and snow in the canopy and the stomatal control of evapotranspiration are parameterized in a highly idealized way. The runoff scheme is based on catchment considerations and takes into account subgrid scale variations of field capacity over inhomogeneous terrain [Dümenil and Todini, 1992].

To study the impact of cirrus clouds on climate and climate sensitivity, two classes of model experiments (XM2, XP2) have been performed (Table 1) where "M2" and "P2" denote the globally uniform perturbation of the prescribed climatological sea surface temperature (SST minus $2 \mathrm{~K}$ and plus $2 \mathrm{~K}$, respectively) and " $X$ " denotes the infrared emissivity of high-level 
"cirrus" clouds (i.e., all clouds above a height corresponding to a pressure level of $400 \mathrm{hPa}$ ). In the "standard" simulations $(X=S)$, cirrus emissivity $(\varepsilon)$ is computed as a function of the simulated cloud water path (CWP)

$$
\varepsilon=1-\exp (-\alpha C W P),
$$

with $\alpha=0.144 \mathrm{~m}^{2} / \mathrm{g}$ [Stephens, 1978], while in the sensitivity experiments, the cirrus emissivity is either set to 0 (transparent cirrus, $X=T$ ) or it is set to 1 (black cirrus, $X=B$ ). In all experiments the shortwave cloud optical properties are computed from the simulated cloud water content as explained earlier. For economical reasons the model simulations are performed in the so-called perpetual mode at a relatively low horizontal resolution (T21) with prescribed SST and solar irradiance representative for the month of July. The diurnal variation of the insolation is retained, however. The total simulation time is 720 days in each experiment. We allow for an initial model spin-up of 90 days, and the last 630 days are used for analyzing the respective model climate.

\section{Model Validation}

The design of the model experiments performed in this study (perpetual mode, SST perturbation) does not allow a comparison with observational data. On the other hand, the ECHAM3 model, among many others, has been integrated over a period of 10 years within the so-called Atmospheric Model Intercomparison Project (AMIP) where monthly observed SSTs and sea ice limits for the period 1979-1988 are prescribed as lower boundary conditions [Gates, 1992]. The AMIP period has four years overlapping with the observational period of the Earth Radiation Budget Experiment (ERBE) (1985-1990), and top-of-atmosphere (TOA) radiative fluxes as obtained from ERBE are used to validate the model with respect to cloud radiative processes. To take advantage of the whole ERBE data set, the AMIP experiment has been extended to January 1990 , and a few results of this experiment are discussed below. To minimize the sampling problem, most of the results are presented as zonal averages. The analysis is confined to latitudes less than $60^{\circ}$ because of difficulties in distinguishing between clear and overcast regions at high latitudes [Ramanathan et al., 1989]. The AMIP version of the ECHAM3 model is different from that used in this study in two numerical aspects, namely, higher horizontal resolution (T42 instead of T21) and Eulerian advection of water vapor and cloud water instead of semi-Lagrangian advection. However, the physical package remains unchanged. Test integrations with both model versions on the basis of climatological SSTs

Table 1. List of Experiments

\begin{tabular}{|c|c|c|c|}
\hline Experiment & $\begin{array}{c}\text { Perturbation of } \\
\text { Climatological } \\
\text { July SST }\end{array}$ & $\begin{array}{l}\text { Cirrus } \\
\text { Emissivity }\end{array}$ & Comment \\
\hline SM2 & $-2 K$ & variable & reference simulation \\
\hline TM2 & $-2 \mathrm{~K}$ & 0 & transparent cirrus \\
\hline BM2 & $-2 \mathrm{~K}$ & 1 & black cirrus \\
\hline SP2 & $+2 \mathrm{~K}$ & variable & global warming experiment \\
\hline TP2 & $+2 \mathrm{~K}$ & 0 & $\begin{array}{l}\text { global warming plus } \\
\text { transparent cirrus }\end{array}$ \\
\hline BP2 & $+2 \mathrm{~K}$ & 1 & $\begin{array}{l}\text { global warming plus } \\
\text { black cirrus }\end{array}$ \\
\hline
\end{tabular}

SST, sea surface temperature.
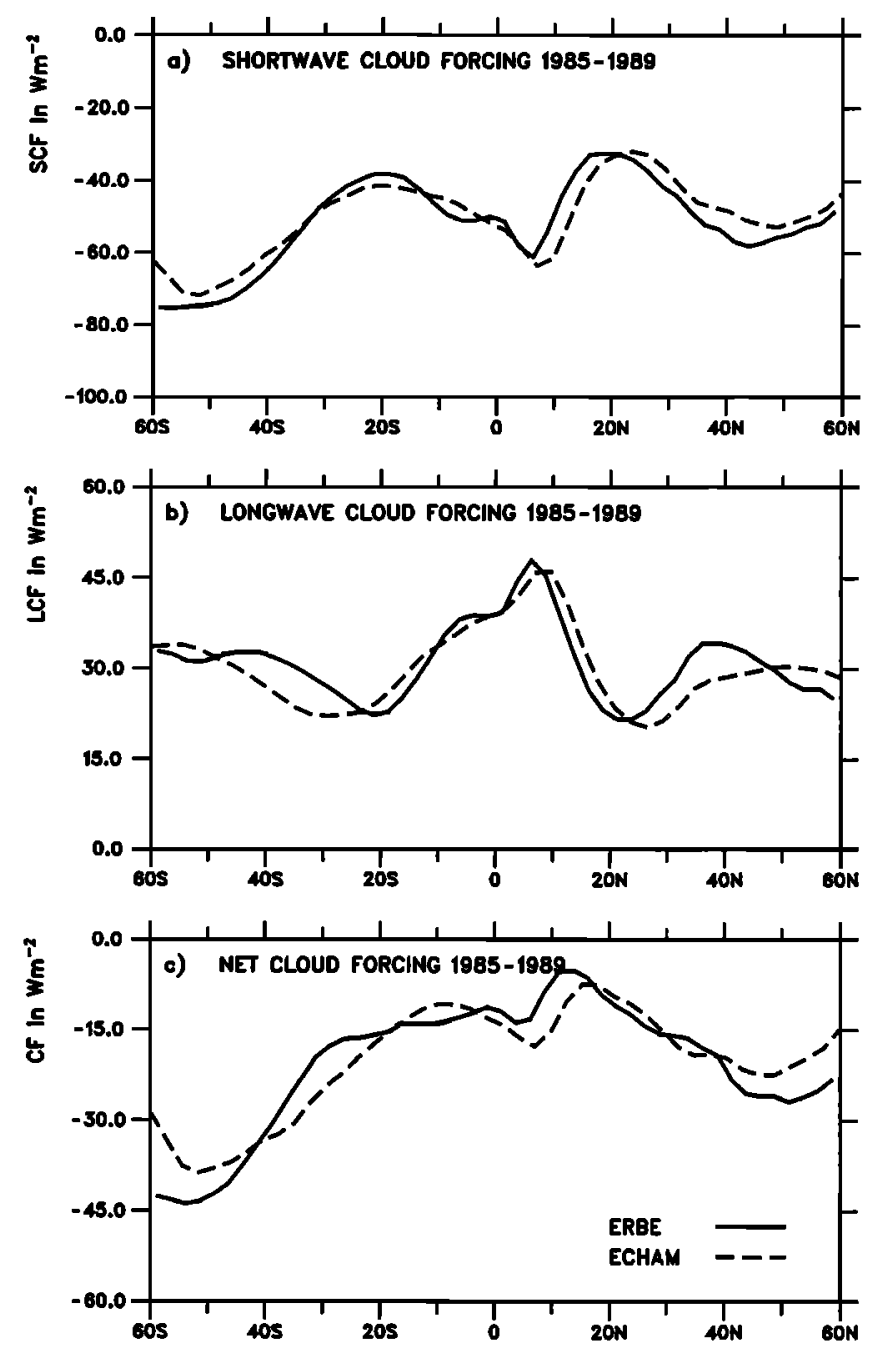

Figure 1. Comparison of simulated (ECHAM) and observed (Earth Radiation Budget Experiment (ERBE)) 5-year mean, zonally averaged cloud forcing as a function of latitude.

confirm that the large-scale distribution of the TOA radiative fluxes is unaffected by the change in the numerical scheme.

In accordance with the main objectives of this study, it is of particular interest to analyze the performance of the model with respect to cloud radiative processes. The impact of clouds on the TOA radiation balance is most conveniently described by the cloud radiative forcing (hereinafter referred to as cloud forcing (CF)). Following the conventional notation [e.g., $R a$ manathan et al., 1989], CF is defined in terms of the emitted longwave radiation $F$, the solar irradiance $S_{0}$, and the albedo $\alpha$ according to

$$
\mathrm{CF}=\mathrm{LCF}+\mathrm{SCF}=\left(F_{c s}-F\right)-S_{0}\left(\alpha-\alpha_{c s}\right)
$$

where the subscript $c s$ is used for clear-sky quantities and LCF and SCF represent the longwave and shortwave components of $\mathrm{CF}$, respectively.

Figure 1 demonstrates that the zonal and annual means of SCF, LCF, and CF, respectively, are reproduced remarkably well by the model, and in most regions the simulation is within the bounds of observational error, typically $5-10 \mathrm{~W} / \mathrm{m}^{2}$ for zonal means. In particular, the model is able to reproduce the observed minimum of net cloud radiative cooling in the tropics 

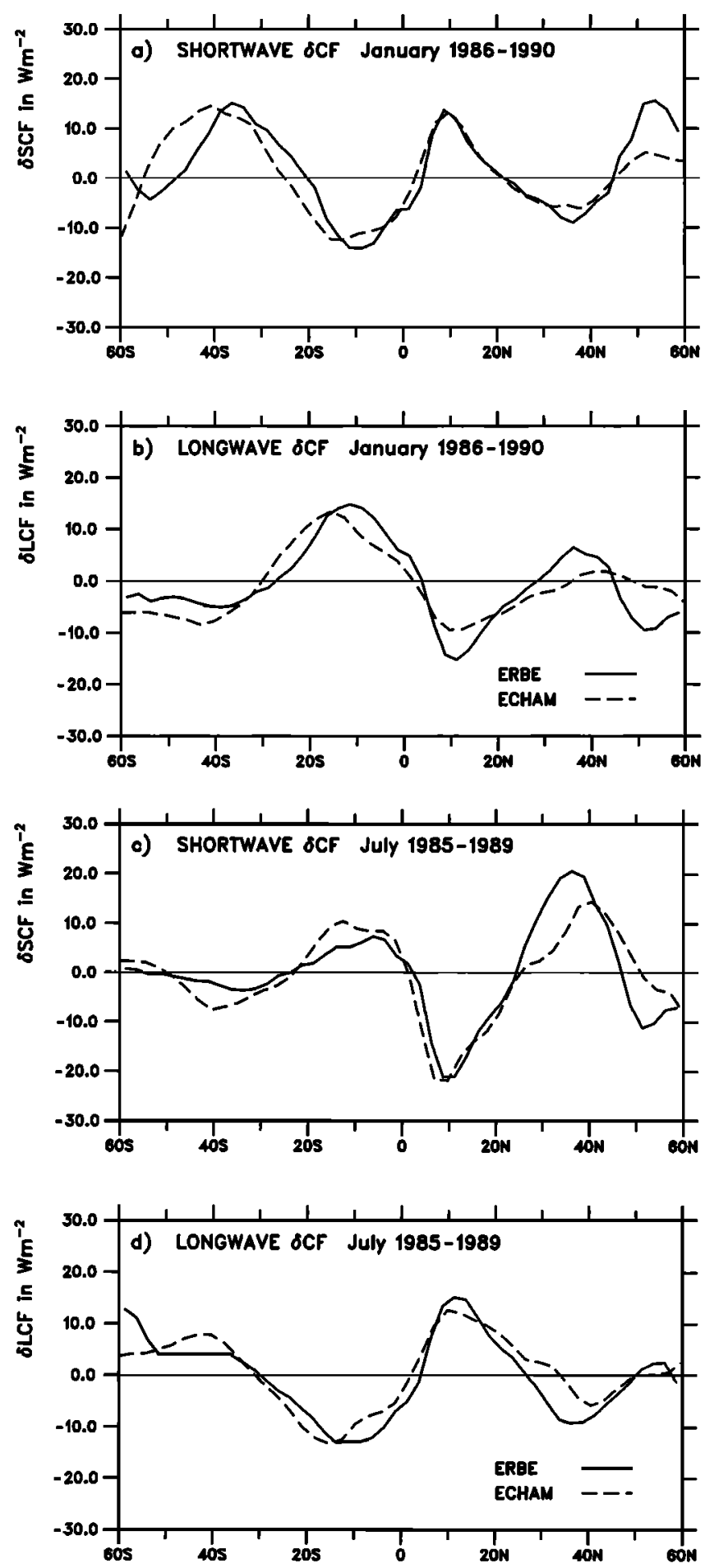

Figure 2. Comparison of simulated (ECHAM) and observed (ERBE) zonally averaged seasonal cloud forcing as a function of latitude for the months of ( $a$ and b) January and (c and d) July, respectively.

resulting from a near cancelation of the cloud greenhouse effect and the cloud albedo effect [Kiehl, 1994].

Furthermore, we ask whether the model is able to simulate the observed CF variations associated with the seasonal solar forcing. According to Cess et al. [1992] the response $\delta \mathrm{CF}$ to seasonal forcing is obtained from definition (2) by subtracting the respective annual mean but neglecting the purely astro- nomical contribution due to the seasonal variation of the solar irradiance, so that

$$
\delta \mathrm{CF}=\delta \mathrm{LCF}+\delta \mathrm{SCF}=\left(\delta_{a} F_{c s}-\delta_{a} F\right)+S_{0}\left(\delta_{a} \alpha_{c s}-\delta_{a} \alpha\right)
$$

where the operator $\delta_{a}$ denotes the seasonal perturbation of a given quantity about its annual mean value. According to definition (3) a positive (negative) number indicates seasonal cloud radiative warming (cooling) due to seasonal variations of cloudiness.

Figure 2 shows that in the extreme months (January, Figures $2 a$ and $2 b$, and July, Figures $2 c$ and $2 d$, respectively) both components of $\delta \mathrm{CF}$ are reproduced with reasonable skill. Since the seasonal variation of $S_{0}$ is neglected, $\delta \mathrm{CF}$ is generated by seasonal changes of radiatively relevant cloud parameters, such as fractional cover, height, depth, and optical properties. In the tropics, for example, most of the signal results from the seasonal shift of the intertropical convergence zone (ITCZ) with a $\delta \mathrm{SCF}$ cooling and $\delta \mathrm{LCF}$ warming, respectively, in the summer hemisphere and vice versa in the winter hemisphere. Although the model is able to capture the broad features of the observed response to seasonal forcing, the amplitude of the longwave component, in particular, is slightly underestimated.

Finally, we assess the skill of the model in simulating the cloud radiative response to interannual SST variations in the tropical Pacific. There is ample evidence from both observations and models that much of the interannual variability in the tropics is related to the warm and cold phases of El Niño Southern Oscillation (ENSO). The observational record between 1981 and 1988, for example, shows a high degree of coherence among the anomalies of SST, zonal wind, and outgoing longwave radiation [Rasmussen, 1991] and atmospheric GCMs when forced with observed SST have shown some skill in reproducing various features of the observed atmospheric response [Lau, 1985; Barnett et al., 1991; Peterson et al., 1992].

In this section we investigate whether the ECHAM3 model is able to reproduce the observed (ERBE) cloud forcing anom-

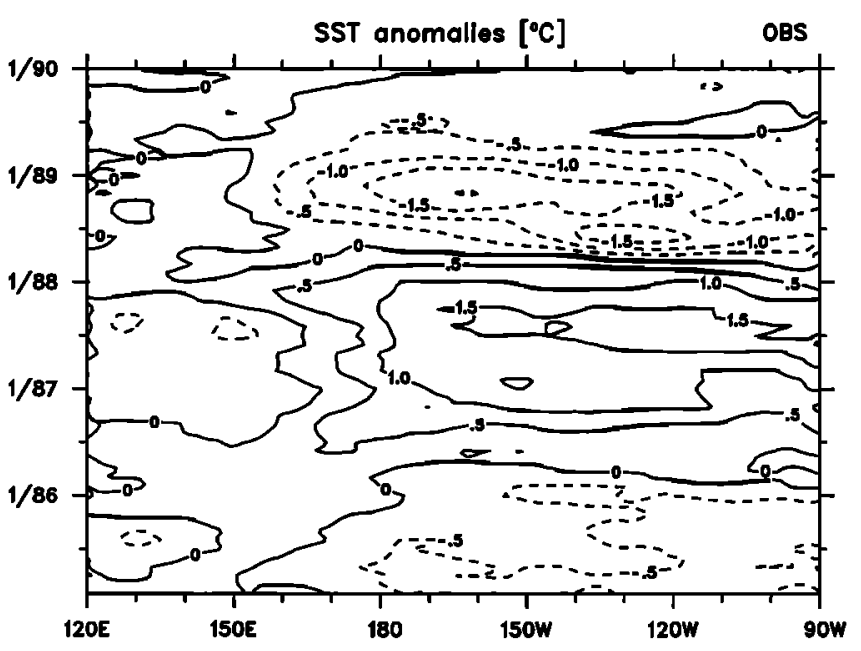

Figure 3. Time-longitude (Hovmöller) diagram of sea surface temperature (SST) anomalies (difference with respect to the mean 1985-1989) in the equatorial Pacific averaged over the latitude belt $5^{\circ} \mathrm{N}-5^{\circ} \mathrm{S}$ as obtained from the Atmospheric Intercomparison Project (AMIP) SST and sea ice data set. Contour spacing is $0.5 \mathrm{~K}$. 
alies in the equatorial Pacific during the 5-year period of February 1985 to January 1990. Figure 3 shows a Hovmöller diagram of SST anomalies with respect to this period, averaged over the latitude belt $5^{\circ} \mathrm{N}-5^{\circ} \mathrm{S}$. The SST anomaly pattern is characterized by a warm event in 1986/1987 with peak values of about $2^{\circ} \mathrm{C}$ in mid- 1987 and a cold event about a year later with a similar amplitude. Figure 4a shows the respective anomalies of the longwave cloud forcing as obtained from ERBE data. Positive LCF anomalies start to develop in the West Pacific during 1985 and propagate slowly eastward until they cover the whole East Pacific during the mature phase of ENSO in 1987 with maximum heating of more than $40 \mathrm{~W} / \mathrm{m}^{2}$ between $160^{\circ}$ and $170^{\circ} \mathrm{W}$. At the same time a slight LCF cooling is observed in the anomalously cold West Pacific indicative of reduced convective activity and cloud cover. The LCF cooling propagates eastward and reaches its peak value of about $-40 \mathrm{~W} / \mathrm{m}^{2}$ at the date line about one year later during the mature phase of the cold event. The ECHAM3 model is able to capture both phase and amplitude of the observed LCF response with reasonable skill (Figure 4b). The peak LCF warming during 1987 is slightly overestimated, however, while the cooling in 1988 spreads over a larger area and the maximum cooling is smaller

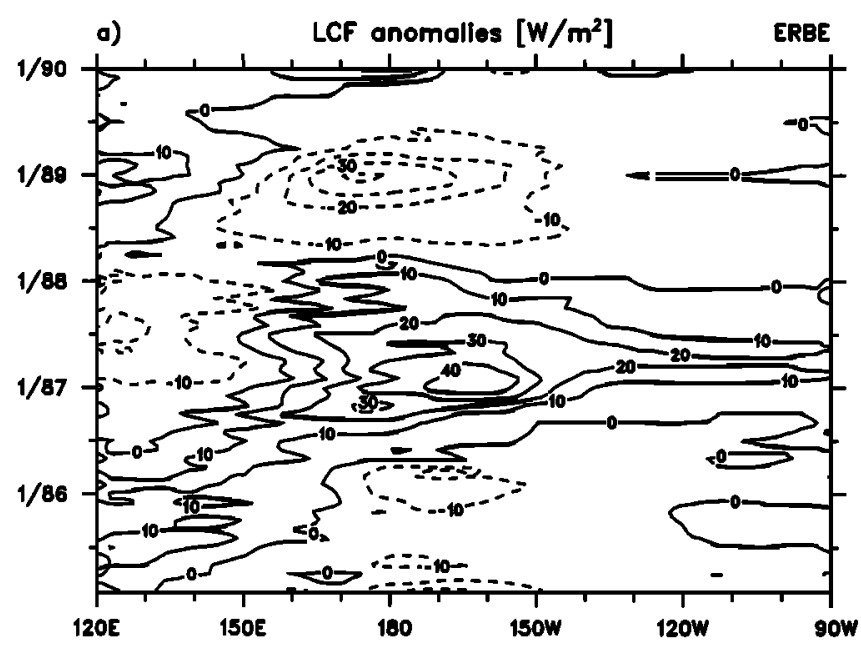

b)

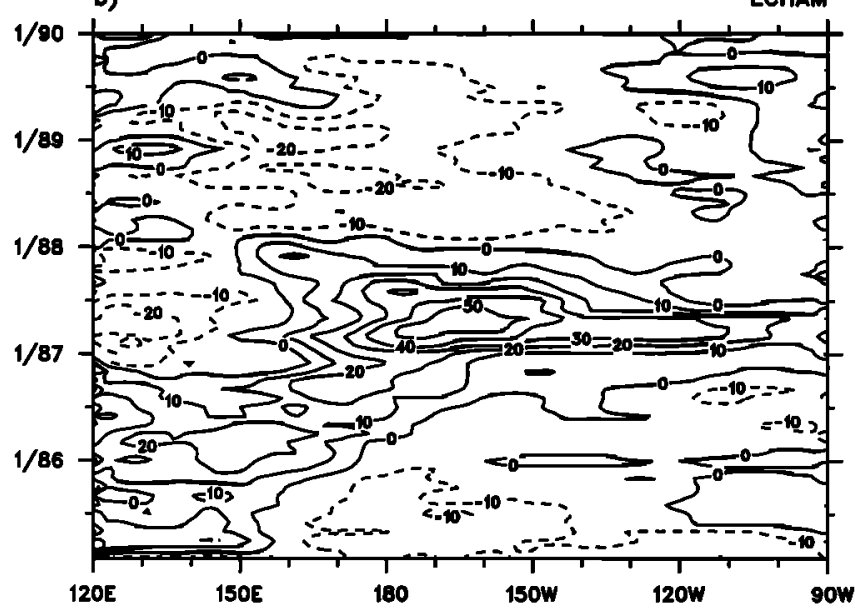

Figure 4. Hovmöller diagram of (a) observed (ERBE) and (b) simulated (ECHAM) anomalies of the top-of-atmosphere longwave cloud forcing (LCF) in the equatorial Pacific, averaged over the latitude belt $5^{\circ} \mathrm{N}-5^{\circ} \mathrm{S}$. Contour spacing is 10 $\mathrm{W} / \mathrm{m}^{2}$. a)

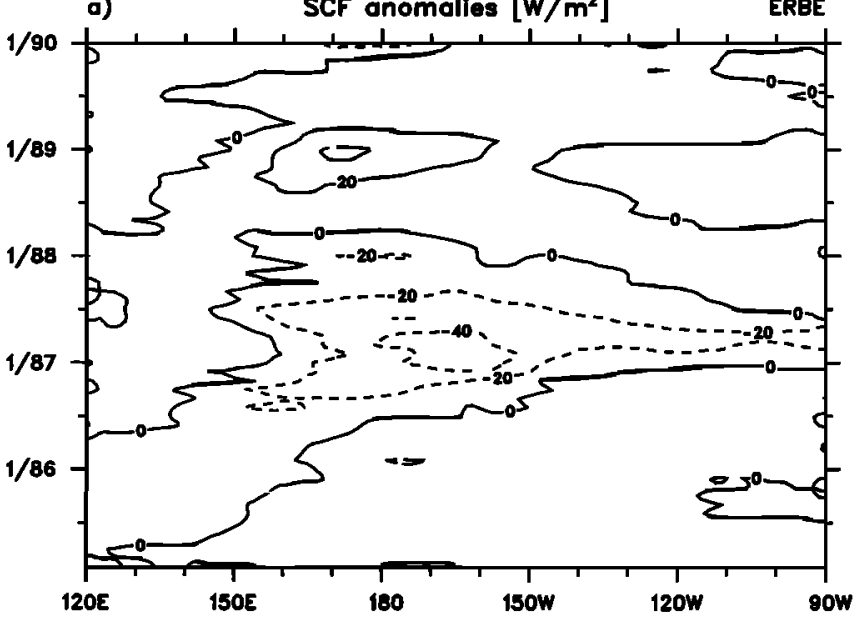

b)

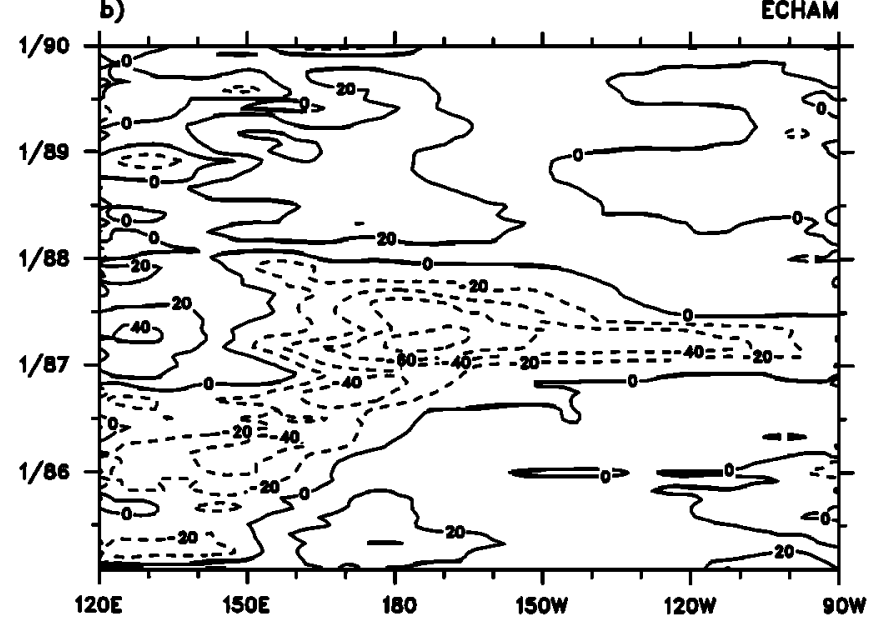

Figure 5. As Figure 4 except for the anomalies of the shortwave cloud forcing (SCF). Contour spacing is $20 \mathrm{~W} / \mathrm{m}^{2}$.

than the observations suggest. The SCF response (Figure 5) is roughly the mirror image of the LCF response, and this applies to both the observed pattern (Figure 5a) and the simulated one (Figure 5b). However, the simulated SCF anomalies are generally larger than the observed ones, particularly during the evolution of the warm event and also during its mature phase in 1987.

Further evidence for the skill of the ECHAM3 model to reproduce the observed characteristics of radiation in the tropics, such as the super greenhouse effect [Ramanathan and Collins, 1991] and the near-cancelation of the longwave and shortwave cloud forcing [Kiehl and Ramanathan, 1990], can be found in the paper of Sherwood et al. [1994].

The physical processes behind the changes documented in Figures 4 and 5 have been analyzed in the past by means of observations and numerical modeling. Over the tropical oceans, convective cloud clusters form predominantly in those areas where the SST exceeds a threshold of about 300K [ Graham and Barnett, 1987]. A second necessary requirement for triggering convection is low-level moisture convergence. Both conditions are fulfilled, for example, in the West Pacific warm pool area where intense convection, large amounts of precipitation, and extended cloudiness is observed during the whole year. The radiative effect of convective cloud clusters is dominated by thick anvils (both geometrically and optically) and 
thinner stratiform cirrus which warm the troposphere and cool the ocean [Ramanathan and Collins, 1991]. During El Niño events the warming of the central and eastern equatorial Pacific sets up a convergence in the atmospheric boundary layer (ABL) which determines to first order the position of convection and cloud formation. The associated condensational heating drives a secondary circulation cell which feeds back positively on the ABL structure [Lindzen and Nigam, 1987; Barnett et al., 1991]. The results presented in section 4 indicate that cloud radiative heating due to the formation of cirrus anvils may also play a role in maintaining this feedback loop.

\section{Response Experiments}

In this section the climate response to changes of cirrus cloud emissivity and global SST perturbation is analyzed. As mentioned earlier, the cirrus emissivity is either calculated (SM2, SP2), set to 0 (TM2, TP2) or set to 1 (BM2, BP2). Hence the difference (TM2-SM2) or (TP2-SP2) is a measure for the impact of the longwave cirrus cloud forcing, while (BM2-SM2) or (BP2-SP2) indicates its potential role in a black cirrus world. Since the results of the cirrus response experiments are virtually independent of the choice of the SST perturbation, we restrict ourselves to the discussion of (TM2SM2) and (BM2-SM2). The black cirrus response is of particular interest, since previous global warming experiments which took into account changes of the cloud optical properties [Roeckner et al., 1987; Mitchell et al., 1989; Le Treut and Li, 1991; Taylor and Ghan, 1992; Senior and Mitchell, 1993] suggested an increase of cloud water content and hence cirrus emissivity in a warmer climate. Statistical significance is not an issue in this paper because most of the changes discussed below are significant at a high level (>99\%).

\subsection{Zonally Averaged Circulation}

Most of the responses discussed below are triggered by a prescribed or simulated change in cirrus cloud emissivity. Figure $6 \mathrm{~b}$ shows the zonal mean cloud emissivity as a function of latitude and height, as simulated in the reference experiment SM2. A comparison with the simulated temperature distribution, shown in Figure 6a, suggests a close correspondence between cloud emissivity and temperature with clouds being almost black on average $(\varepsilon>99 \%)$ in areas where the temperature is higher than about $-20^{\circ} \mathrm{C}$. In the other extreme, clouds are optically thin $(\varepsilon<10 \%)$ in areas where the temperature is extremely low, such as the Antarctic vortex in winter or the tropopause region.

Consistent with the strong dependency of $\varepsilon$ on $T$ is the increase of cloud emissivity in the global warming experiment $\mathrm{SP} 2$, as shown in Figure 6c. The largest increase of $\varepsilon$ (more than $25 \%$ ) is simulated at low latitudes around $200 \mathrm{hPa}$ and over Antarctica below about $500 \mathrm{hPa}$. The change of $\varepsilon$ in experiments TM2 and BM2, respectively, is not shown because it can easily be inferred from Figure 6b: According to the design of experiment BM2 the change of cirrus emissivity (above $400 \mathrm{hPa}$ ) is just given by $1-\varepsilon(\mathrm{SM} 2)$, increasing from 0 at $400 \mathrm{hPa}$ to nearly 1 at the tropopause level. Conversely, in the transparent cirrus experiment TM2, the change of $\varepsilon$ above $400 \mathrm{hPa}$ is defined as $-\varepsilon(\mathrm{SM} 2)$.

The resulting temperature changes are shown in Figure 7. As compared to the reference run, the transparent cirrus assumption leads to a general tropospheric cooling and to a stratospheric warming (Figure 7a). The opposite response is
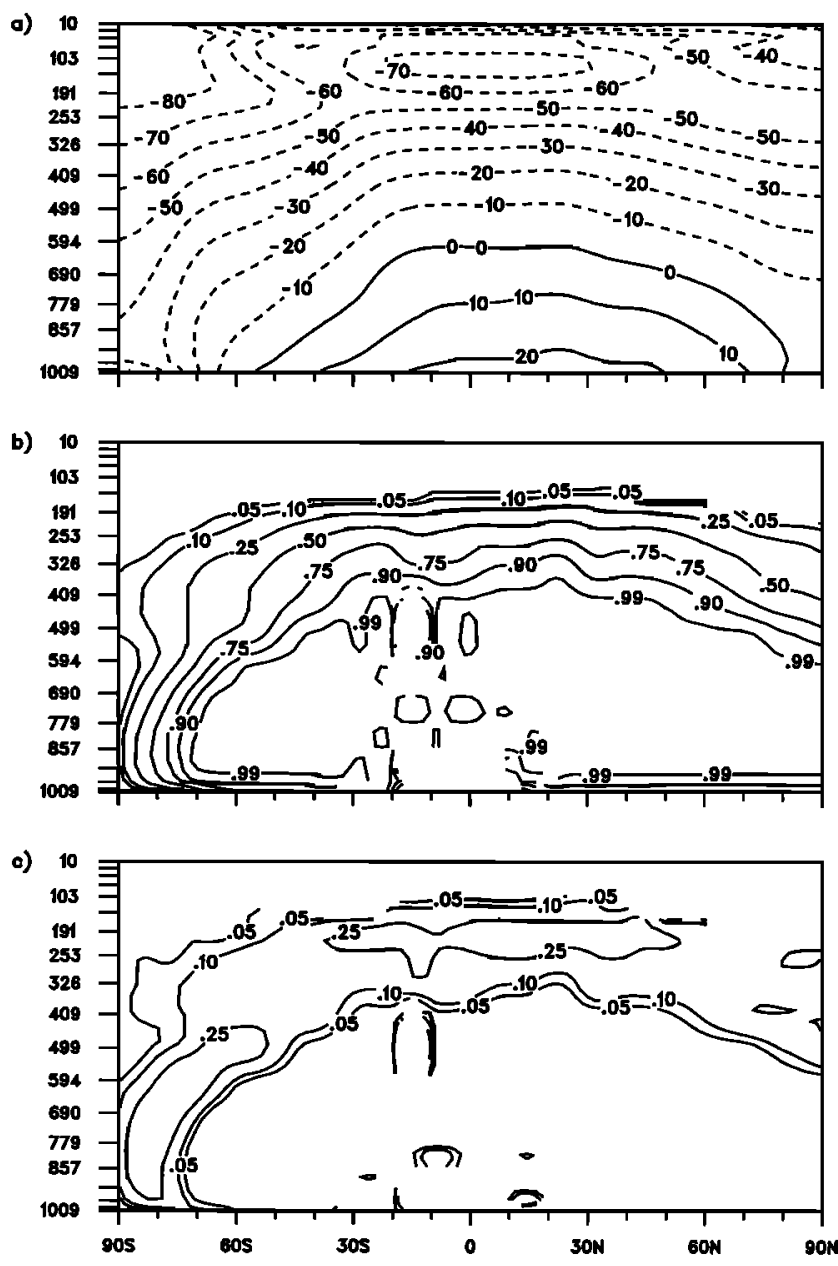

Figure 6. Latitude-pressure distribution of zonally and timeaveraged (a) temperature, (b) cloud emissivity, both for the reference experiment SM2, and (c) emissivity change in the global warming experiment SP2, as compared to the reference experiment SM2. Contour spacings is $10^{\circ} \mathrm{C}$ for temperature and $0.05,0.1,0.25,0.5,0.75,0.90$, and 0.99 for emissivity and emissivity change. Areas with cloud cover below $2 \%$ are left blank.

found in the black cirrus experiment (Figure 7c) with a tropospheric warming of up to $10 \mathrm{~K}$ below the tropical tropopause and in the global SST warming experiment SP2 (Figure 7b) with a tropical upper tropospheric warming of more than $8 \mathrm{~K}$ which is more than twice the warming prescribed at the sea surface. The main difference between the global warming response (heat source at the ground) and the black cirrus response (heat source in the upper troposphere) is the larger vertical gradient of the tropical warming in the latter experiment. Although the design of the cirrus sensitivity experiments is slightly different from that of previous studies conducted with the NCAR CCM model [Ramanathan et al., 1983; Slingo and Slingo, 1988], the temperature change is broadly similar. It differs, however, from that obtained by Randall et al. [1989] with the UCLA/GLA model suggesting an upper tropospheric warming if all clouds were assumed radiatively inactive and a general tropospheric warming when only the cirrus anvils were removed in the experiment. On the other hand, Randall et al. obtained a response more similar to ours in their "sea world" scenario where all land areas had been replaced by ocean, thus 
a)

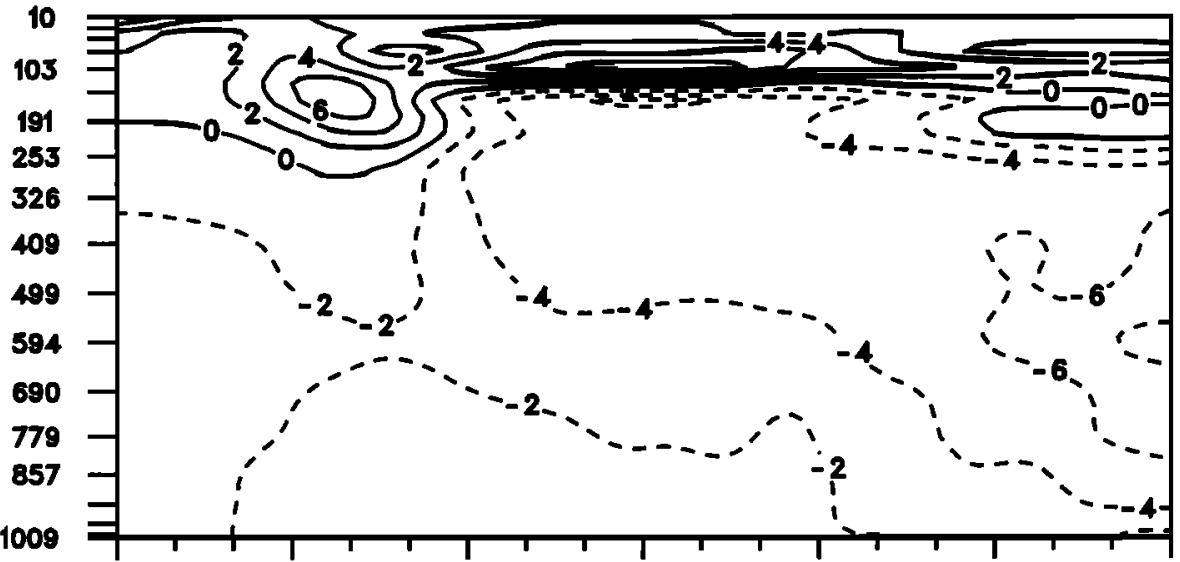

b) 10

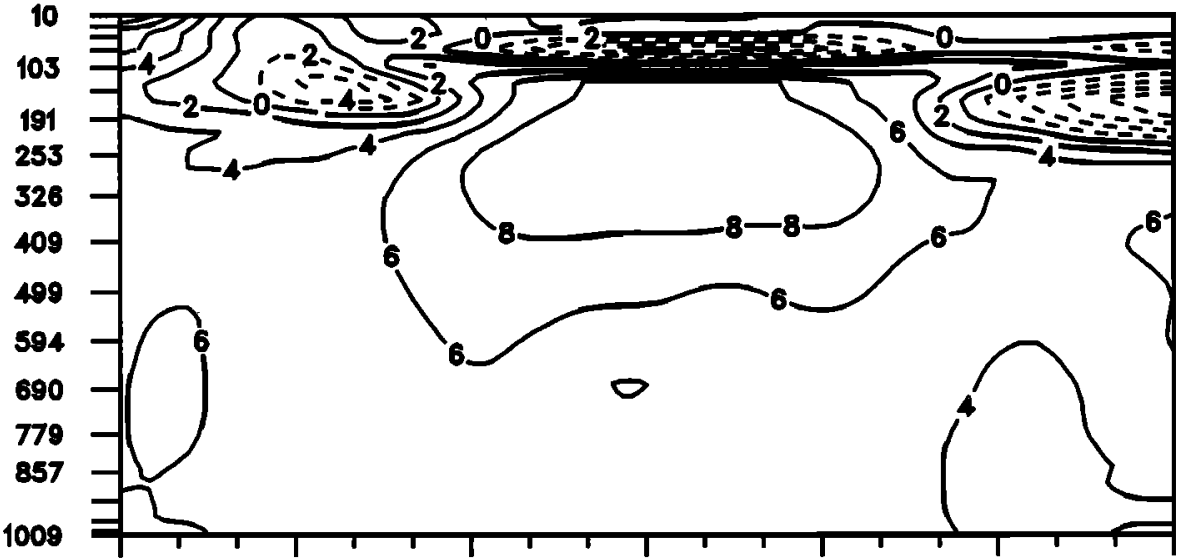

0)

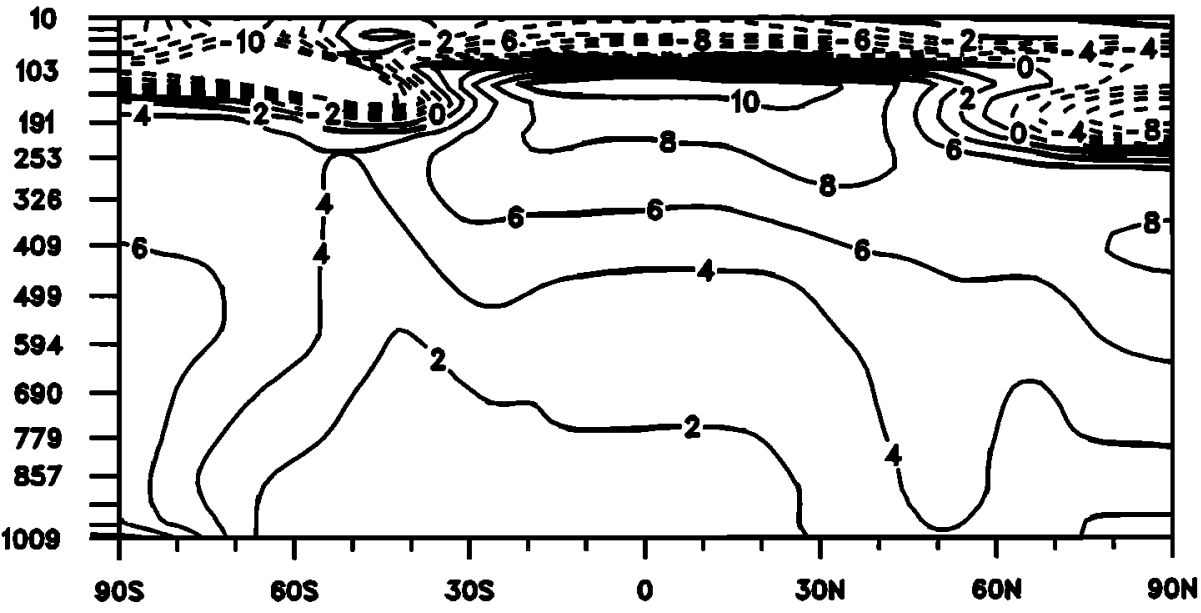

Figure 7. Latitude-pressure distribution of zonally and time-averaged temperature differences between experiments and reference experiment: (a) TM2-SM2, (b) SP2-SM2, (c) BM2-SM2. Contour spacing is $2 \mathrm{~K}$.

eliminating all indirect effects by modifications of the land surface temperature.

Consistent with the changed temperature distribution documented in Figure 7 is the change of the zonally averaged circulation such as the zonal wind or the Hadley cell (not shown) with the flow and the hydrological cycle, in particular, becoming stronger with increasing cloud emissivity. This response is broadly similar to that obtained by Ramanathan et al. [1983], Slingo and Slingo [1988], and also Randall et al. [1989] in their sea world scenario. The general conclusion which can be drawn from these studies is that the radiative heating of the atmosphere by clouds has a substantial impact on the strength of the general circulation through interactions among radiation, the hydrological cycle, and largescale dynamics. In the following subsections we study to what extent these interactions are relevant for interpreting the dynamic response to a global SST warming. In particular, we address the problem of the zonally asymmetric response of the tropical circulation to a globally uniform SST warming. 

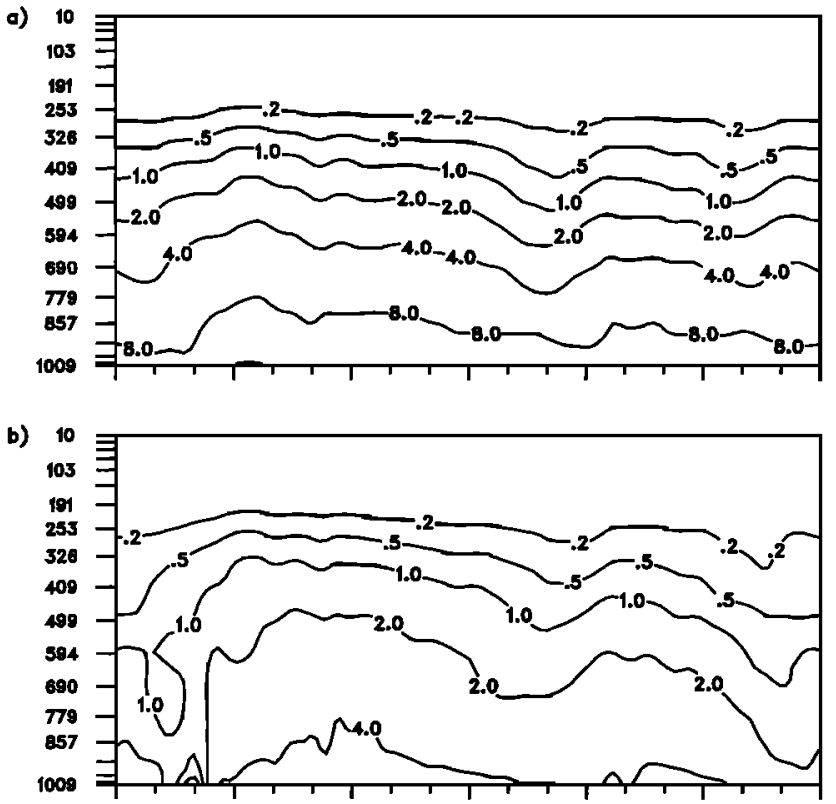

o)

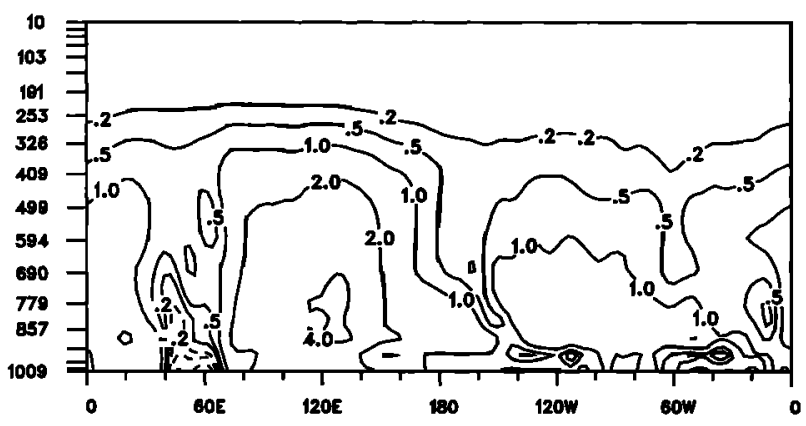

Figure 8. Longitude-pressure distribution of time mean (a) specific humidity in the reference experiment SM2 and humidity differences (b) SP2-SM2 and (c) BM2-SM2, averaged over the latitude belt $0^{\circ}-30^{\circ} \mathrm{N}$. Contour spacing, $\pm 0.2,0.5,1,2,4$, and $8 \mathrm{~g} / \mathrm{kg}$.

\subsection{Zonal Variations in the Tropics}

Because of rapid adjustment processes in the tropics the horizontal temperature gradients above the boundary layer are relatively small (not shown). It is well known from both observations and model simulations that because of rapid adjustment processes in the tropics the temperature distribution is fairly uniform in the west-east direction [Barnett et al., 1991; Wallace, 1992]. Larger horizontal gradients build up, however, in the humidity field with high values in convectively disturbed regions and relatively low values in regions with suppressed convection. The moistening of the main troposphere in areas with high SST and active convection is the major cause for the generation of a so-called super greenhouse effect, as analyzed by Ramanathan and Collins [1991] from ERBE data. Figure 8a shows the specific humidity averaged between $0^{\circ}$ and $30^{\circ} \mathrm{N}$ as a function of longitude and height, as simulated in the reference experiment SM2. Particularly at high altitudes, there is a marked increase of specific humidity across the tropical Pacific with a relatively dry eastern Pacific and a relatively moist western Pacific and Indian Ocean. The respective changes in the global warming experiment SP2 and in the black cirrus experiment BM2 are shown in Figures $8 \mathrm{~b}$ and $8 \mathrm{c}$, respectively. As to be expected from the substantial tropospheric warming in these experiments (cf. Figures $7 \mathrm{~b}$ and $7 \mathrm{c}$ ), the moisture increases in both experiments throughout the troposphere. In both experiments the largest moistening is simulated in those areas where the moisture is already large in the reference run. Hence the east-west moisture gradient is enhanced in both experiments, particularly in BM2. Because of higher SST in SP2 the moistening is particularly large in the lower troposphere, while the moistening is generally smaller and vertically more uniform in BM2.

Similar to specific humidity, the largest cloud amount is simulated in the West Pacific warm pool area and in the Indian Ocean (including the Asian monsoon area) with the deepest clouds in the Indian Ocean and over the Indian subcontinent between about $60^{\circ} \mathrm{E}$ and $100^{\circ} \mathrm{E}$, as shown in Figure 9a. A secondary high-cloud maximum is found over Central America, while the cloudiness minima in the surrounding oceans indicate areas with large-scale subsidence.

As apparent from Figures $9 \mathrm{~b}$ and $9 \mathrm{c}$, the cloud responses to global warming and black cirrus, respectively, are similar in structure but different in magnitude. In the global warming experiment SP2 (Figure 9b) the upper level dipole structure, with cloud increase around $100 \mathrm{hPa}$ and decrease below, is related to a lifting of the tropopause [cf. Mitchell and Ingram, 1992]. In the West Pacific warm pool area the increase of midlevel clouds results in a deepening of the cloud layer as compared to the reference run SM2 (Figure 9a). In the black cirrus experiment (Figure 9c) the cloud deepening in the West Pacific is substantially larger with a pronounced westward extension into the Indian Ocean. This structural change of cloudiness is caused by a strong vertical tropospheric heating gradient (cf. Figure 7c) which tends to lower the penetration depth of deep convection. Thus provided that the convection is not shut down completely, cumulus clouds detrain moisture and cloud water already at lower levels and, as a result, cloud formation in the midtroposphere is enhanced. The increase of West Pacific midlevel clouds in the global warming experiment SP2 (Figure 9b) is smaller than in BM2 because the tropical heating is more uniform (cf. Figures $7 \mathrm{~b}$ and $7 \mathrm{c}$ ).

The changes of humidity and cloudiness discussed above are indicative of a changed Walker circulation and/or monsoon circulation. Both are ultimately driven by differential diabatic heating resulting from thermal contrasts between different ocean areas or between ocean and continent. Figure 10 shows the east-west variation of the total diabatic averaged between $0^{\circ}$ and $30^{\circ} \mathrm{N}$ for the reference experiment (Figure 10a), the global warming experiment (Figure 10b) and for the black cirrus experiment (Figure 10c). The total diabatic heating is defined as the sum of radiative heating and phase changes (condensation/evaporation) but includes also the contributions from subgrid scale transports generated by turbulence and convection. Since the atmospheric heat storage vanishes in the long-term mean, the total diabatic heating has to be balanced by the large-scale dynamics. Because of the weak horizontal temperature gradients in the tropics the horizontal heat advection is small, and the diabatic heating is balanced predominantly by adiabatic expansion/compression resulting from large-scale vertical motion. In all experiments, maximum diabatic heating and hence maximum upward motion is simulated in the West Pacific/Indian Ocean area. A weaker heating maximum is found over Central America, while diabatic cooling and hence adiabatic warming due to downward motion is evident over the East Pacific, in particular. The increase of cirrus emissivity (Figure 10b) and the increase of the SST by $4 \mathrm{~K}$ (Figure 10c) result in larger east-west heating gradients which 
a)

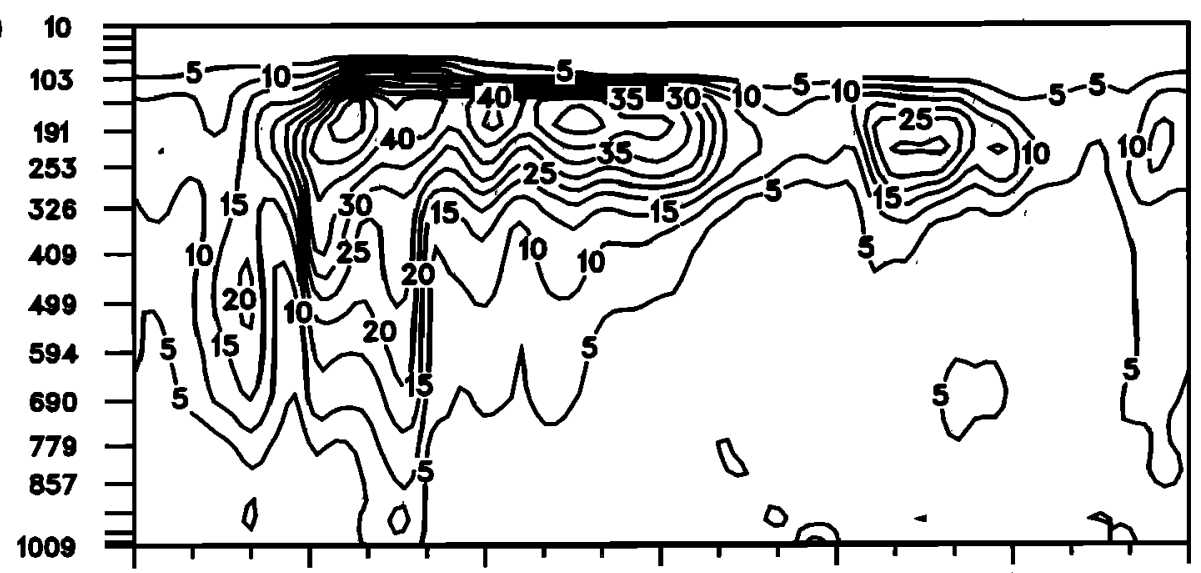

b)

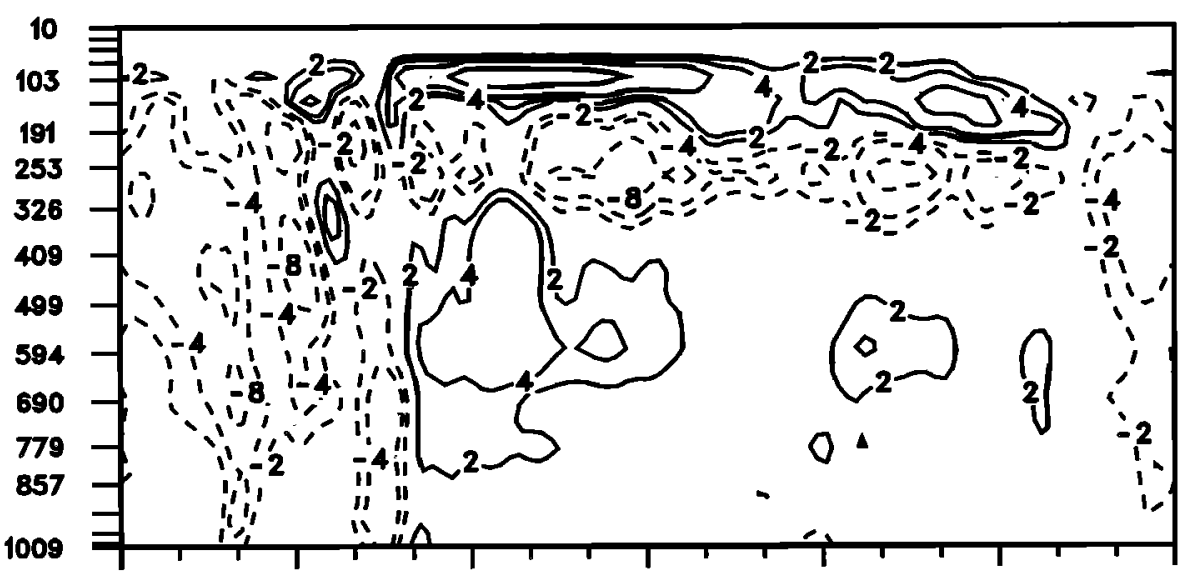

o)

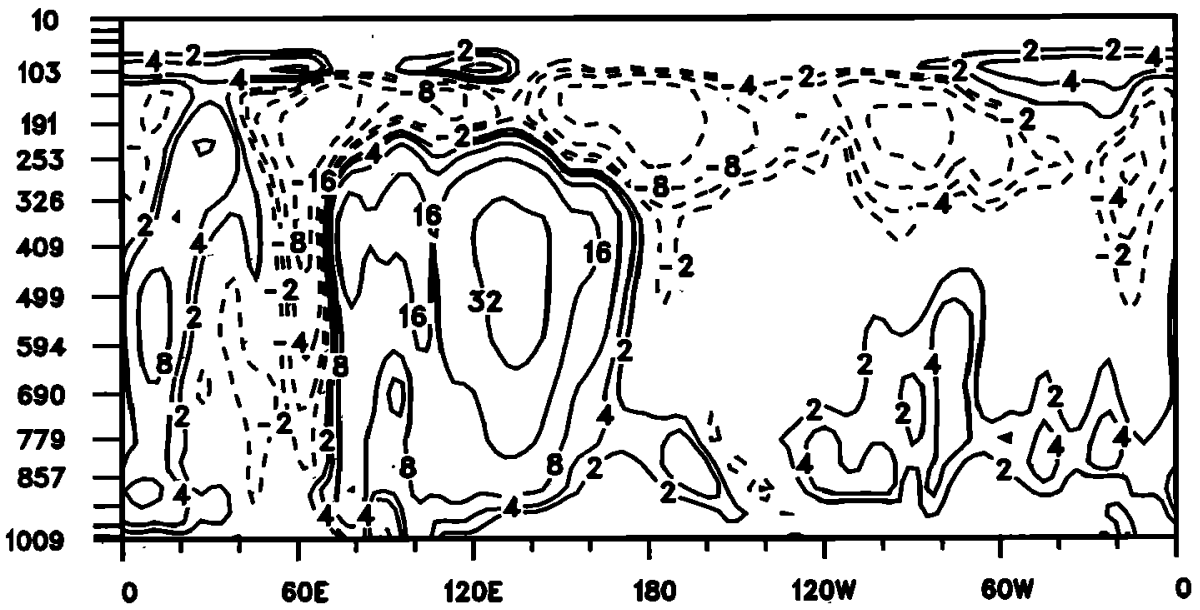

Figure 9. Longitude-pressure distribution of time mean (a) cloud cover in the reference experiment SM2 and cloud cover differences (b) SP2-SM2 and (c) BM2-SM2, averaged over the latitude belt $0^{\circ}-30^{\circ} \mathrm{N}$. Contour spacing, $5 \%$ for cloud cover and $\pm 2,4,8,16$, and $32 \%$ for the differences.

can be related to a strengthened Walker circulation. It is interesting to note that in the black cirrus experiment BM2 (Figure 10c) a sign reversal of the diabatic heating is simulated near cloud tops with cooling above the thick clouds in the West Pacific and Indian Ocean area and warming in regions where upper level clouds are less abundant, as in the Atlantic region, for example. As is shown later, this diabatic heating structure is related to cloud radiative processes which trigger a reverse Walker cell in the upper troposphere and lower stratosphere with sinking air over the convectively active regions and rising air over areas where high-level clouds are less abundant. The net radiative warming of thin cirrus layers below the tropical tropopause has been proposed as one of the mechanisms providing a transfer of water vapor from the troposphere to the stratosphere in the real world [Gage et al., 1991].

A further indication of the cirrus radiative impact on the strength of the Walker circulation is shown in Figure 11. The quadrupole structure of the velocity potential with upper level 
a)

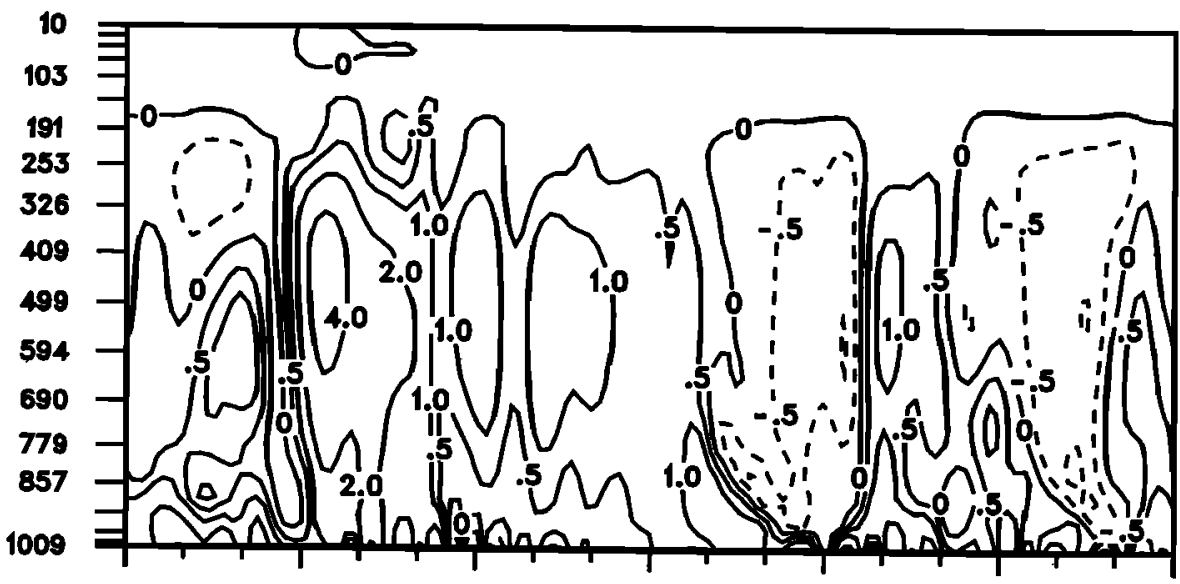

b)

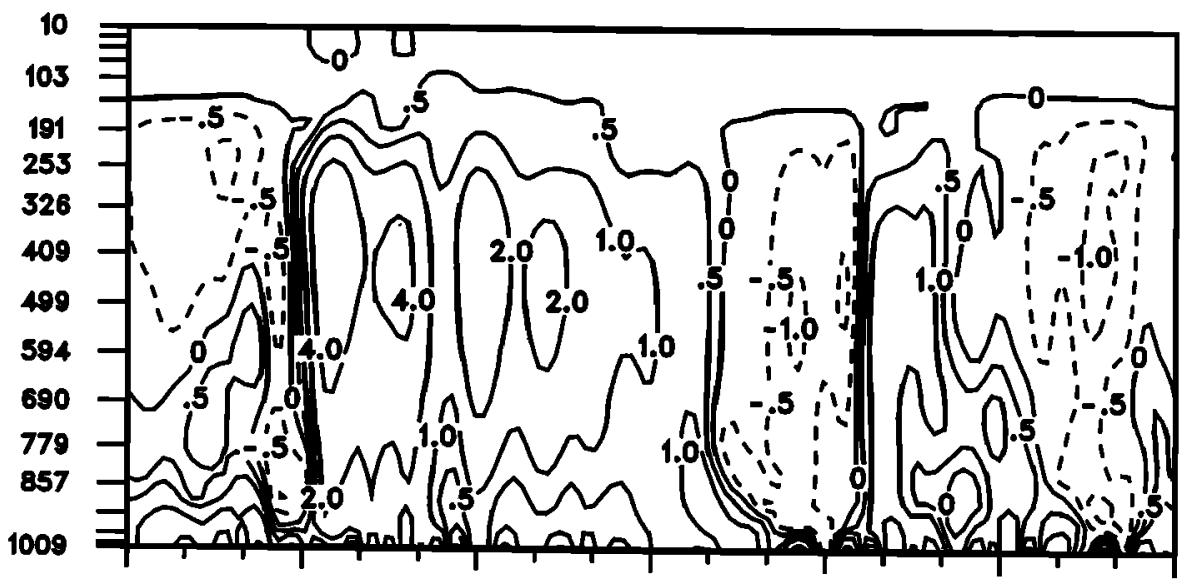

o)

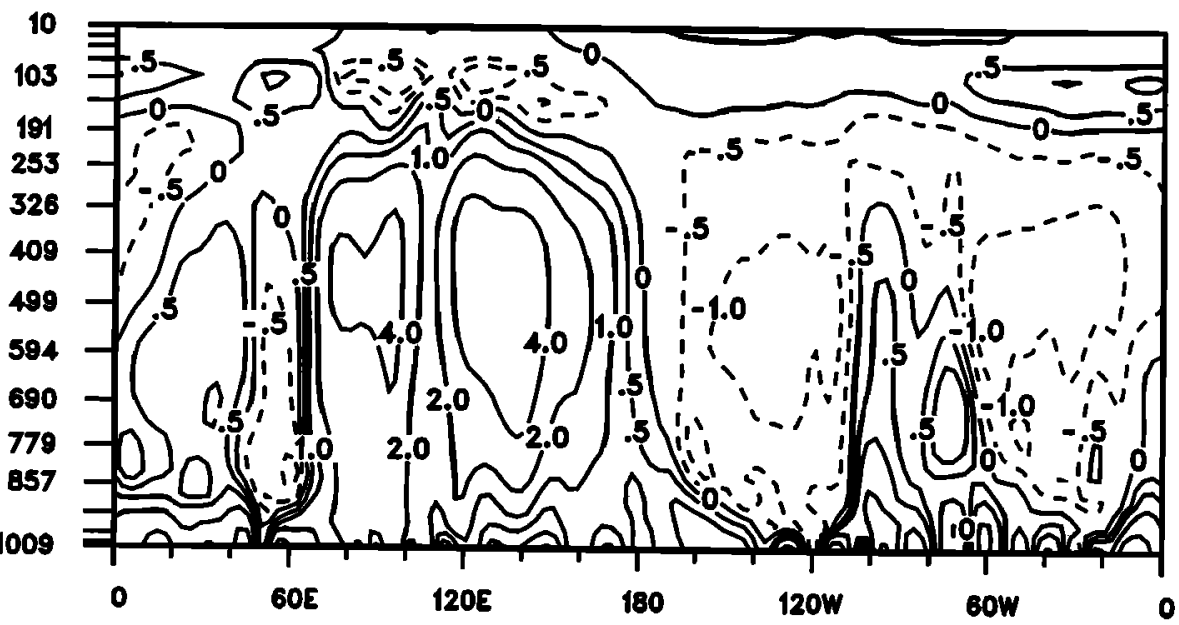

Figure 10. Longitude-pressure distribution of time mean diabatic heating in the experiments (a) SM2, (b) SP2, and (c) BM2, averaged over the latitude belt $0^{\circ}-30^{\circ} \mathrm{N}$. Contour spacing, $\pm .5,1,2,4$, and $8 \mathrm{~K} / \mathrm{d}$.

divergence and low-level convergence in the convectively active regions, and vice versa in regions with suppressed convection, is progressively intensified from top to bottom of Figure 11 with the weakest gradients both horizontally and vertically in the transparent-cirrus experiment (Figure 11a) and the largest gradients in the other extreme of black cirrus above $400 \mathrm{hPa}$ (Figure 11d). As compared to the reference run (Figure 11b), the global warming results in an intensi- fication of the Walker cell (Figure 11c), but the increase is smaller than in the black cirrus case.

\subsection{Atmospheric Heating Profiles in the Tropical West} Pacific

To study the contribution of individual terms of the thermodynamic equation to the changed Walker circulation, we selected an area which comprises the West Pacific warm pool, 
a)
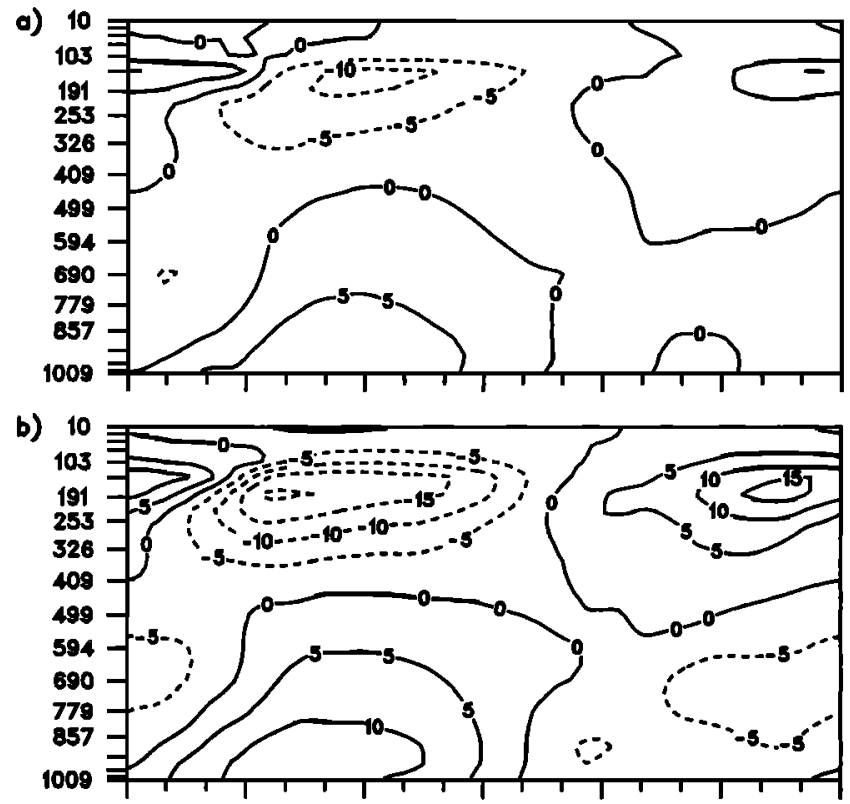

c)

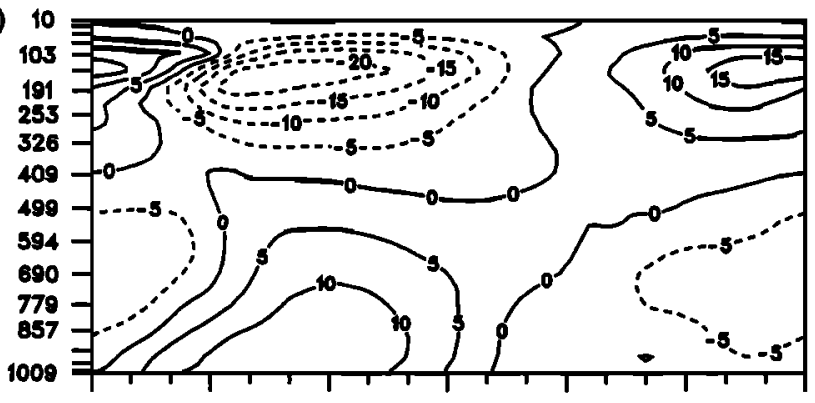

d)

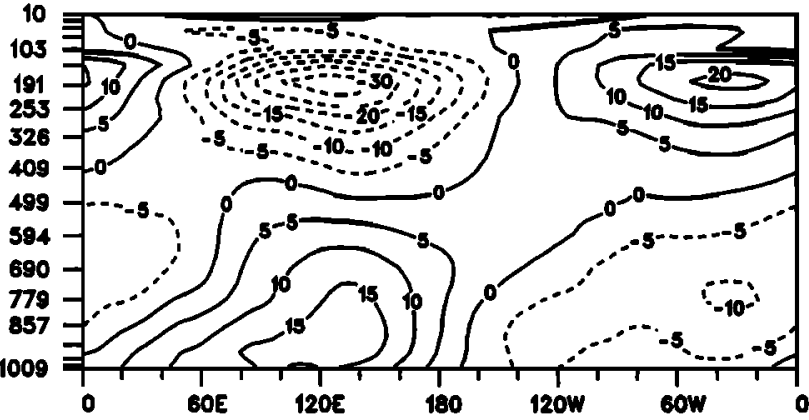

Figure 11. Longitude-pressure distribution of time mean velocity potential in the experiments (a) TM2, (b) SM2, (c) SP2, and (d) BM2, averaged over the latitude belt $0^{\circ}-30^{\circ} \mathrm{N}$. Contour spacing is $5 \mathrm{~km}^{2} / \mathrm{s}$.

the Indian Ocean including the Arabian Sea, the Bay of Bengal, the Indian subcontinent, and South East Asia $\left(0^{\circ}\right.$ to $30^{\circ} \mathrm{N}$; $60^{\circ} \mathrm{E}$ to $150^{\circ} \mathrm{E}$ ). During boreal summer this area is marked by organized deep convection, nonconvective mesoscale cirrus and cirrus anvils between about 200 and $500 \mathrm{hPa}$ [Fu et al., 1990]. The vertical cloud structure in the reference experiment can be inferred for that area from Figure 9a. It is also the area where the responses to cirrus cloud and SST changes are largest (cf. Figures 9b, 9c, and Figure 10).

Figure 12 shows vertical distributions of the shortwave and longwave cloud forcing (SCF and LCF, respectively), averaged over the area mentioned above for the transparent cirrus run (Figure 12a), the reference run (Figure 12b), the global warming experiment (Figure 12c), and the black cirrus experiment
(Figure 12d). In all experiments the upper troposphere above about $600 \mathrm{hPa}$ is heated by absorption of solar radiation in clouds ( $\mathrm{SCF}>0$ ), while the lower troposphere is cooled as compared to a cloud-free reference atmosphere $(\mathrm{SCF}<0)$ because less solar radiation is available for heating the atmosphere below cloud base. Conversely, LCF is positive throughout the troposphere except at cloud tops just below the tropopause level where net infrared cooling is simulated as a result of cloud top emission (LCF $<0$ ). However, because of the design of the transparent cirrus experiment (Figure 12a), LCF is zero in the upper troposphere, while LCF cooling is shifted to the middle troposphere. As compared to the reference run (Figure 12b), the global warming experiment (Figure 12c) shows an enhancement of both SCF in the upper levels and LCF in the lower levels resulting from an increase of cloud cover, cloud water content (not shown), and hence cloud emissivity (cf. Figure $6 \mathrm{c}$ ). Similarly but even more pronounced, both SCF and LCF increase in the black cirrus run, partly due to the design of the experiment and partly as a result of the increased cloudiness (cf. Figure 9c). In the other extreme the transparent cirrus experiment (Figure 12a) shows a reduction of both SCF and LCF throughout the troposphere, indicative of a weakening of convective activity and cloud generation processes in this area. It is interesting to note further that the month-to-month variability (expressed in terms of standard deviation) increases with increasing cirrus emissivity.

The major components of the atmospheric heat budget in the area mentioned above are shown in Figure 13. In the reference run SM2 (Figure 13b) the free troposphere is heated by convection with a maximum of nearly $3 \mathrm{~K} / \mathrm{d}$ between about 500 and $600 \mathrm{hPa}$. The convective heating is balanced by radiative and adiabatic cooling in the rising branches of the Walker circulation and the Asian summer monsoon circulation. Heating by turbulent diffusion is essentially confined to the boundary layer, while heating through condensation in stratiform (large scale) clouds becomes important only in the upper troposphere above about $500 \mathrm{hPa}$.

In the global warming experiment (Figure 13c) this balance remains essentially unchanged except that nearly all terms become larger. The increased diabatic warming by enhanced convection and large-scale condensation is balanced by a larger adiabatic cooling. In the black cirrus experiment BM2 (Figure 13d) the dynamic response is slightly larger than in SP2, particularly in the lower troposphere, but the compensation is achieved in a different way. The strong upper tropospheric warming in BM2 results in a reduction of convective activity, while at the same time the heating by the release of latent heat in large-scale clouds becomes the dominant term in the upper troposphere. Furthermore, the large cloud radiative heating (cf. Figure 12d) is able to almost offset the clear-sky radiative cooling, so that the net radiative cooling becomes very small. Because of the black cirrus assumption the upper part of the cloud layer between about $200 \mathrm{hPa}$ and $75 \mathrm{hPa}$ is cooled radiatively, and the heat balance is achieved by a corresponding dynamical warming resulting from sinking motion. In the transparent cirrus case TM2 (Figure 13a) the convection is substantially weakened, the radiative cooling is slightly increased because the cloud radiative forcing is small (cf. Figure 12a), and the reduced convective heating is balanced essentially by a smaller adiabatic cooling which is diminished to roughly $50 \%$ of that simulated in the reference run SM2.

Similar results were obtained by Slingo and Slingo [1988] with the NCAR CCM, Randall et al. [1989] with the UCLA/ 

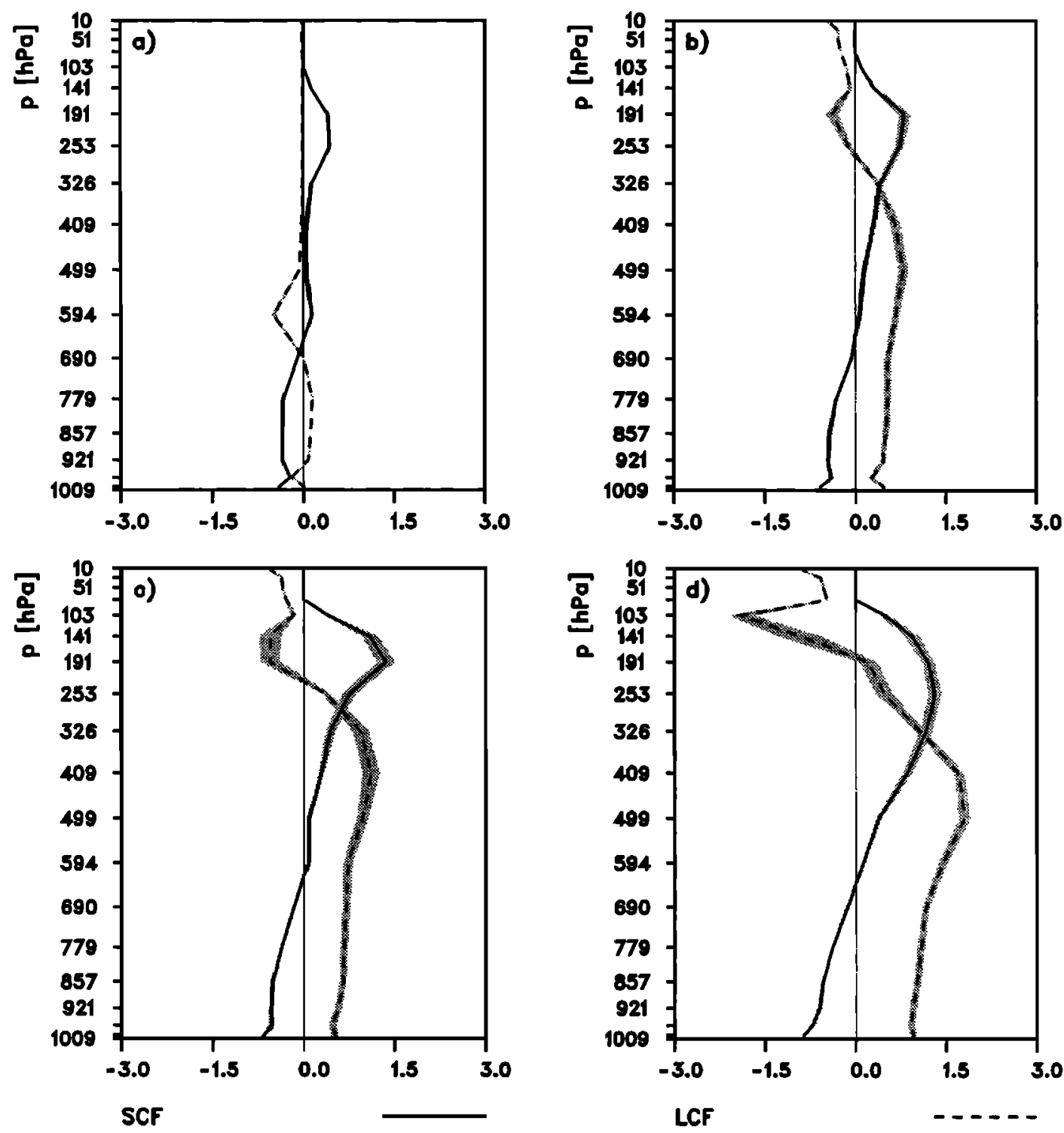

Figure 12. Vertical profiles of SCF and LCF averaged between $0^{\circ}-30^{\circ} \mathrm{N}$ and $60^{\circ} \mathrm{E}-150^{\circ} \mathrm{E}$ for the experiments (a) TM2, (b) SM2, (c) SP2, and (d) BM2. Units, K/d. Shading indicates standard deviations of monthly means.

GLA model, and Sherwood et al. [1994] with the ECHAM3 model. Obviously, this radiative-convective-dynamic feedback mechanism is rather insensitive to cumulus closure assumptions which are very different in the three GCMs. While the NCAR model employs a simple moist convective adjustment scheme and the UCLA/GLA model the sophisticated Arakawa/Schubert scheme, the ECHAM3 model uses a bulk mass flux approach with a moisture convergence closure assumption for deep convection. Similar conclusions can be drawn for all other parameterizations such as radiation, cloud formation, and turbulent transfer which are very different as well.

\subsection{Surface Heat and Water Budget}

The changes of the tropical circulation and those of humidity and cloudiness, in particular, documented in Figures 8 to 11, are related to changes of the surface heat and water budget. Figure 14 shows the east-west variation of the respective components averaged over all ocean areas between the equator and $30^{\circ} \mathrm{N}$. The change of cloudiness in the West Pacific and
Indian Ocean (cf. Figure 9) has a substantial impact on the amount of solar radiation absorbed at the surface (Figure 14a). Almost everywhere in this area, the largest amount of solar radiation is absorbed in the transparent cirrus case TM2, while a dramatic decrease from about $250 \mathrm{~W} / \mathrm{m}^{2}$ in SM2 to about 100 $\mathrm{Wm}^{2}$ is simulated in the black cirrus case BM2 in the West Pacific. In the global warming experiment SP2 the response is similar in sign but smaller in magnitude, as compared to BM2. The longwave radiation budget (Figure 14b) changes in the opposite way as a result of atmospheric humidity and cloudiness changes, but the differences are generally smaller than those obtained for the shortwave budget. The sensible heat fluxes (Figure 14c) change in the same sense as the longwave radiation providing a surface heating relative to SM2 in the black cirrus case BM2 and a surface cooling through enhanced fluxes in TM2, largely as a result of the changed temperature in the boundary layer. As for the shortwave radiation budget, the longwave radiation and sensible heat flux responses to global warming are similar in sign but smaller in magnitude than those obtained in BM2. 

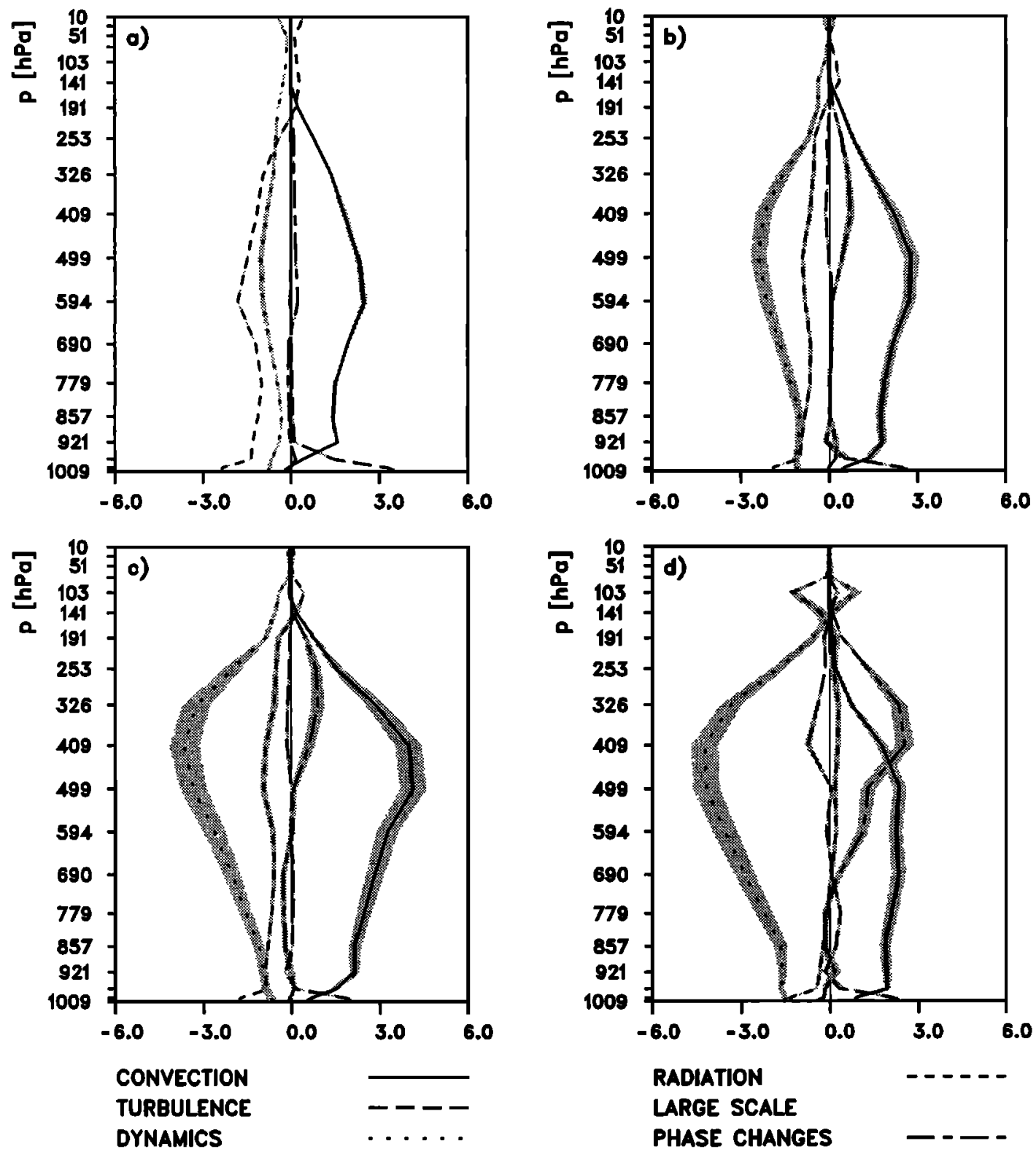

Figure 13. As Figure 12 except for various components of the heat budget equation.

A fundamental difference between SP2 and BM2 can be identified in Figure 14d which shows the latent heat flux distributions for the four experiments. The increase of the latent heat flux throughout the area in SP2 relative to all other experiments is a direct result of the SST warming. On the other hand, the smallest fluxes are simulated in BM2 because the black cirrus warming creates a warmer and moister troposphere. Oppositely, the latent heat flux is generally increased in TM2, due to the colder and dryer troposphere simulated in that experiment. Obviously, an increase of cirrus emissivity favors cloud formation in convectively disturbed regions, while the evaporation at the surface is reduced which immediately raises the question: Where is the moisture source which maintains the enhanced convection or large-scale condensation in the West Pacific warm pool area in the experiments SM2 and BM2 relative to TM2? As the surface evaporation is reduced with increased cirrus emissivity, the only mechanism to provide the required additional moisture convergence is the large-scale circulation. Since a long-term storage of water in the atmosphere can be excluded, the vertically integrated atmospheric moisture convergence is just the difference between precipitation $P$ and evaporation $E$ at the surface, and this difference is actually shown in Figure 14e. All model experiments indicate positive $(P-E)$ in the convectively active regions provided by the excess evaporation (i.e., $E>P$ ) in the relatively dry regions upstream of the convection areas. In the West Pacific warm pool area the largest moisture convergence is simulated in the black cirrus experiment, supplying that region with additional moisture and clouds although the surface evaporation is reduced nearly everywhere. Consequently, the chief mechanisms providing the additional moisture is the acceleration of the circulation (cf. Figure 11). In the global warming experiment, on the other hand, the additional moisture in the West Pacific is provided by both local enhancement of surface evaporation (approximately $0.5 \mathrm{~mm} / \mathrm{d}$ in the warm pool area) and moisture import from remote areas through the trade wind 


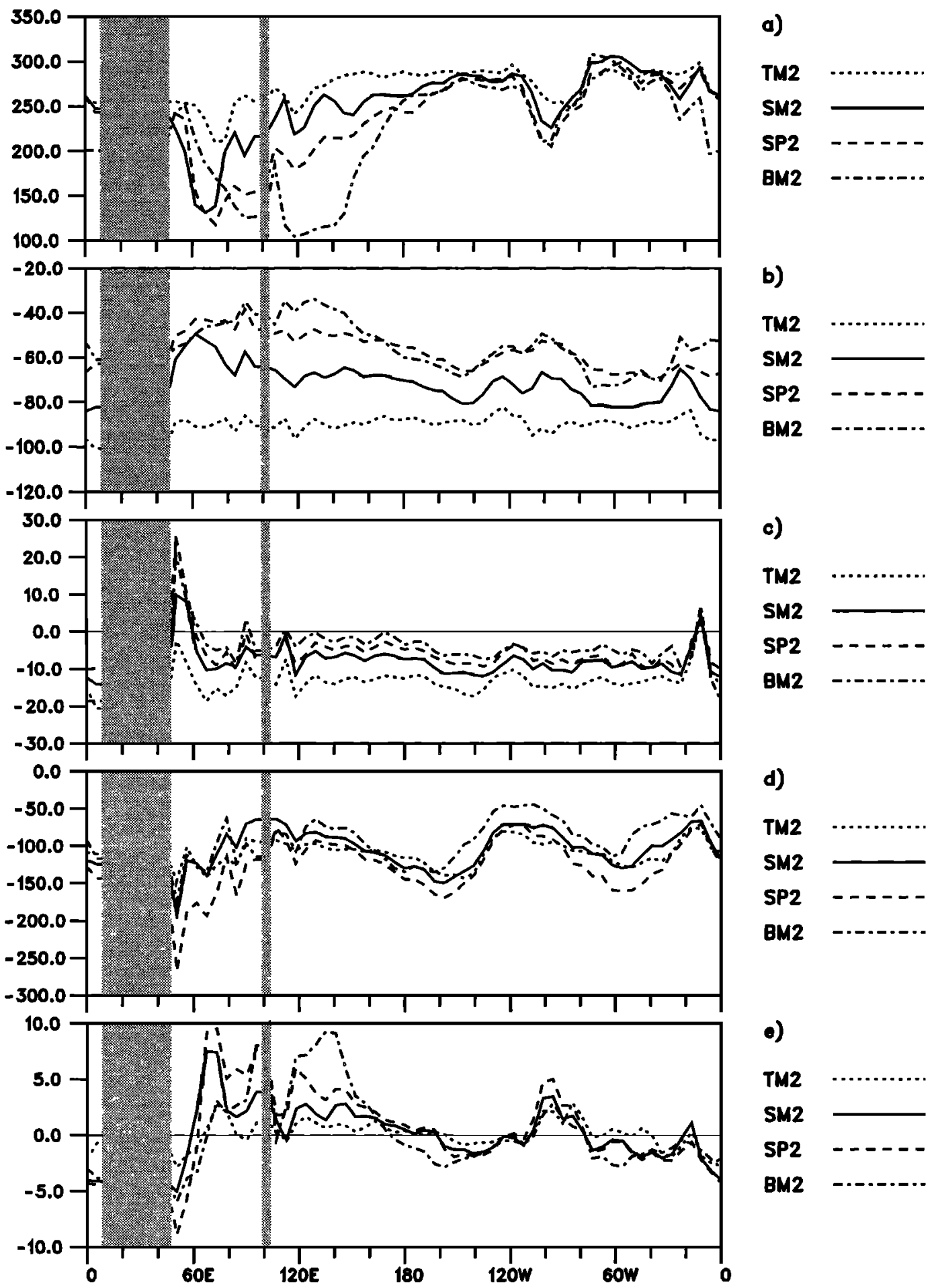

Figure 14. Zonal variation of individual components of the surface heat and water budget, averaged over the latitude belt $0^{\circ}-30^{\circ} \mathrm{N}$ (oceans only): (a) net shortwave radiation, (b) net longwave radiation, (c) sensible heat flux, (d) latent heat flux, and (e) precipitation-evaporation. Upward fluxes are denoted with a negative sign. Units, $\mathrm{W} / \mathrm{m}^{2}$ for energy fluxes and $\mathrm{mm} / \mathrm{d}$ for the water budget.

systems predominantly (roughly $2 \mathrm{~mm} / \mathrm{d}$ in the warm pool area). In the transparent cirrus case TM2 the moisture convergence is very small despite the comparatively large surface evaporation. This result is consistent with the weak tropical circulation simulated in that experiment resulting in small zonal asymmetries of humidity and cloudiness.

The modifications of the surface heat and water budget are not confined to the tropics, however. Table 2 shows global averages of the respective components, the TOA radiation budget, and a few atmospheric parameters in addition, such as total cloud cover (CC), precipitable water (PW), and columnar cloud water $(\mathrm{CW})$. Similar to the changes obtained for the tropical oceans, the magnitude of all surface heat flux components decreases with increasing cirrus emissivity, while the 
most obvious change in the global warming experiment SP2 is an increase of the latent heat flux by about $13 \mathrm{~W} / \mathrm{m}^{2}$. The TOA radiation fluxes change in a similar way as those at the surface, and the response of the longwave flux significantly exceeds the magnitude of the respective shortwave response. Hence, as to be expected, the increase of cirrus emissivity leads to a warming of the atmosphere-surface system. Moreover, increasing the cirrus emissivity from experiments TM2 to SM2 and further to BM2 results in a substantial increase of total cloud cover, precipitable water, and cloud water as well. On the other hand, the global mean precipitation is reduced as is the surface evaporation or latent heat flux, opposite to the change obtained by Randall et al. [1989] who simulated a precipitation decrease of $0.11 \mathrm{~mm} / \mathrm{d}$ in a perpetual January experiment where the longwave cloud radiative forcing was completely removed. In the global warming experiment SP2, on the other hand, the precipitation rate is substantially higher than in SM2, consistent with the increased latent heat flux at the warmer ocean surface, and the outgoing longwave radiation is increased due to the larger infrared emission from the warmer surface. In this respect, the response is fundamentally different from that of the black cirrus experiment. As a result of the atmospheric warming, both components of the atmospheric water content are increased, similar to $\mathrm{BM} 2$, while the total cloud cover is slightly reduced, different from BM2 but consistent with the model responses obtained by Cess et al. [1990] for a suite of GCMs using an identical experimental design (cf. section 5).

It is of interest to discuss the global distribution of the precipitation response (Figure 15). The precipitation simulated in the reference run SM2 is shown in the top panel (Figure 15a), and the differences between the experiments and SM2 are shown in Figures 15b-15d. The response obtained in the TM2 experiment (Figure 15b) is characterized by a spatially coherent precipitation decrease of up to $7 \mathrm{~mm} / \mathrm{d}$ in most of the areas where the tropical precipitation is high in the reference experiment (West Pacific, Arabian Sea, Indian subcontinent, ITCZ over Africa). Precipitation increases in the surrounding ocean areas (southern Indian Ocean and most of the Pacific Ocean) and also to the north and south of the Atlantic ITCZ. This change is similar to that obtained by Slingo and Slingo [1988] and Randall et al. [1989] in perpetual January experiments. The black cirrus response (Figure 15d) is broadly the mirror image of Figure $15 \mathrm{~b}$ with an increase between the Bay of Bengal and the tropical West Pacific of up to $10 \mathrm{~mm} / \mathrm{d}$ and a decrease in the surrounding ocean areas, most notably in the Indian Ocean, in the South Pacific convergence zone (SPCZ), and in the ITCZ. The precipitation response in BM2 is consistent with the respective $(P-E)$ response (cf. Figure $14 \mathrm{e}$ ), indicating an atmospheric moistening of the convectively most active regions and a drying with respect to the reference run SM2 in all other regions.

The response pattern obtained in the SST warming experiment (Figure 15c) bears some resemblance to that of the black cirrus experiment (Figure 15d) with the largest increase in those areas where the precipitation is large already in the reference run. On the other hand, the precipitation decrease in the surrounding areas is either smaller than in BM2 or completely missing, as for example in convectively active regions such as the ITCZ or the SPCZ where the precipitation actually increases as a result of local evaporation enhancement. In this respect, the response of the global warming experiment is different from that of the black cirrus experiment.
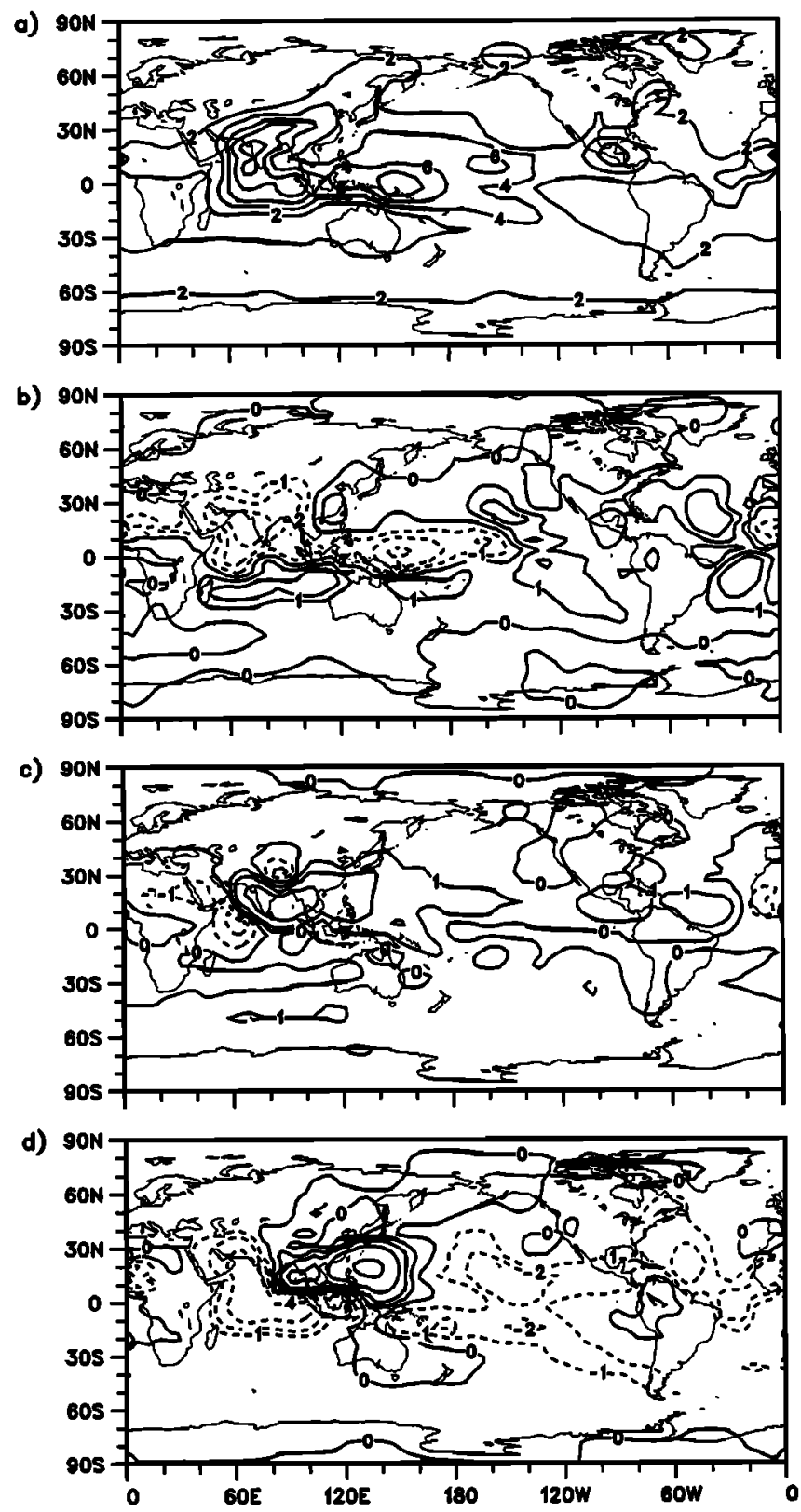

Figure 15. Geographical distribution of (a) precipitation in the reference experiment SM2 and precipitation differences (b) TM2-SM2, (c) SP2-SM2, and (d) BM2-SM2. Contour spacing, $2 \mathrm{~mm} / \mathrm{d}$ for SM2 and $\pm 1,2,4,8$, and $16 \mathrm{~mm} / \mathrm{d}$ for the differences.

\section{Global Climate Sensitivity}

The response of the climate system to a radiative perturbation resulting from an instantaneous doubling of the atmospheric $\mathrm{CO}_{2}$ concentration, for example, depends on a variety of poorly understood feedback mechanisms [International Panel on Climate Change (IPCC), 1990]. One of the most complex and uncertain processes is the cloud-radiationtemperature feedback which involves large but partly compensating changes of the radiative fluxes, so that even the sign of the feedback is uncertain [Cess et al., 1990].

In this section we analyze the impact of high-level cirrus clouds on global climate sensitivity. The experimental setup 
Table 2. Global Means of Surface (sfc) Heat Budget Components $\left(\mathrm{W} / \mathrm{m}^{2}\right)$

\begin{tabular}{ccccccccccc}
\hline Experiment & SW $_{\text {sfc }}$ & LW $_{\text {sfc }}$ & SH & LH & SW $_{\text {toa }}$ & LW $_{\text {toa }}$ & $P$ & PW & CW & CC \\
\hline TM2 & $\mathbf{1 7 7 . 7}$ & -84.4 & -22.5 & -74.6 & 240.1 & -249.0 & 2.57 & 18.1 & 38.9 & 50.8 \\
SM2 & $\mathbf{1 6 9 . 0}$ & -72.8 & -18.9 & -71.8 & 234.0 & -233.2 & 2.47 & 21.9 & 55.6 & 53.4 \\
SP2 & $\mathbf{1 6 5 . 7}$ & -65.4 & -17.3 & -84.7 & 232.2 & -239.1 & 2.91 & 31.0 & $\mathbf{6 6 . 5}$ & 52.2 \\
BM2 & $\mathbf{1 5 6 . 3}$ & $-\mathbf{6 2 . 0}$ & -16.7 & -56.8 & 225.6 & -208.2 & 1.95 & 27.0 & $\mathbf{8 4 . 2}$ & 55.1
\end{tabular}

SW, net shortwave radiation; LW, net longwave radiation; SH, sensible heat flux; LH, latent heat flux; top-of-atmosphere (toa) net shortwave and longwave radiation $\left(\mathrm{W} / \mathrm{m}^{2}\right)$; precipitation $P(\mathrm{~mm} / \mathrm{d})$; precipitable water PW $\left(\mathrm{kg} / \mathrm{m}^{2}\right)$; column-integrated cloud water content $\mathrm{CW}\left(\mathrm{g} / \mathrm{m}^{2}\right)$; and total cloud cover $\mathrm{CC}$ (\%). A negative sign indicates upward fluxes.

and the analysis method is identical to that used by Cess et al. [1990]. Climate sensitivity is defined here as the TOA radiative response to a global SST forcing which can be regarded as a surrogate climate change. In the reference experiment the climatological July SST is cooled everywhere by $2 \mathrm{~K}$, while it is heated by $2 \mathrm{~K}$ in the climate warming experiment. Three pairs of experiments are performed with variable (i.e., computed) cirrus emissivity, transparent cirrus, and black cirrus, respectively (Table 1). As mentioned earlier, the simulation time is 720 days in each experiment, but the initial spin-up period of 90 days is not considered in the analysis. Following Cess et al., the climate sensitivity parameter is defined as

$$
\lambda=\left(\Delta F / \Delta T_{s}-\Delta Q / \Delta T_{s}\right)^{-1}
$$

where $\Delta T_{s}$ is the global mean surface warming and $\Delta F$ and $\Delta Q$ are the changes of the global mean TOA longwave emission $F$ and net solar radiation $Q$, respectively. The so-called method II [Cess and Potter, 1987] is used to compute the radiative fluxes at every model time step in a clear-sky reference atmosphere, while all other parameters such as temperature, humidity, etc., remain unchanged. Accordingly, a clearsky sensitivity parameter $\lambda_{c s}$ can be defined which has the same form as $\lambda$ with the radiative responses $\Delta F$ and $\Delta Q$ replaced by the respective clear-sky values,

$$
\lambda_{c s}=\left(\Delta F_{c s} / \Delta T_{s}-\Delta Q_{c s} / \Delta T_{s}\right)^{-1}
$$

Thus $\lambda / \lambda_{c s}$ can be regarded as a measure of cloud feedback with $\lambda / \lambda_{c s}>1$ denoting a positive cloud feedback and $\lambda / \lambda_{c s}$ $<1$ a negative one. It was further shown by Cess et al. [1990] that the cloud feedback parameter $\lambda / \lambda_{c s}$ is proportional to the change of cloud forcing $\triangle \mathrm{CF}$,

$$
\lambda / \lambda_{c s}=1+\Delta \mathrm{CF}(\Delta F-\Delta Q)^{-1}
$$

with the cloud forcing CF as defined by (2).

The results are summarized in Table 3. Although the water vapor content in the three control experiments (TM2, SM2, BM2) is remarkably different (Table 2), with global mean PW differences of up to $50 \%$, the clear-sky sensitivity $\lambda_{c s}$ which is largely a measure of the water vapor feedback, is very similar in the three model versions. All of the $\lambda_{c s}$ fall into the comparatively narrow range of model sensitivities analyzed by Cess et al. [1990]. This applies also to the global sensitivity $\lambda$ for which the simulated range is much larger, however, because the models do not agree on magnitude and sign of cloud feedback. Actually, the intermodel $\lambda$ variations analyzed by Cess et al., are much larger than those obtained in this study with different versions of the ECHAM3 model.

In the $T$ model, $\lambda$ is reduced with respect to its clear-sky value by $20 \%$. This negative cloud feedback is caused by a systematic increase of the cloud water content and cloud op- tical depth in the warmer atmosphere resulting in a highercloud albedo so that $\Delta \mathrm{SCF}$ is negative $\left(-1.65 \mathrm{~W} / \mathrm{m}^{2}\right)$, despite the fact that the total cloud cover is reduced by nearly $3 \%$. Since, in this experiment, high clouds above $400 \mathrm{hPa}$ are transparent in the infrared, the change of cloud emissivity is confined to the lower layers where most clouds (except at high latitudes) are already black in the reference experiment. Therefore the change of cloud emissivity contributes very little to the total cloud feedback, and the negative $\triangle \mathrm{LCF}$ which even enhances the negative cloud feedback is simply caused by the diminished cloud cover.

In the standard model $(S)$ where the cirrus emissivity is computed as a function of the cloud water content, clouds enhance the global sensitivity by nearly $20 \%$, so that the cloud feedback is positive. The $\lambda$ value of $0.56 \mathrm{~K} /\left(\mathrm{Wm}^{-2}\right)$ falls in the middle range of simulated sensitivities [Cess et al., 1990]. It is close to that obtained for the AMIP version of the ECHAM3 model $\left(0.53 \mathrm{~K} / \mathrm{Wm}^{-2}\right)$, suggesting that neither the horizontal resolution nor the advection scheme used for the water components have a decisive impact on global sensitivity (cf. section 3 ). In the $S$ model, the shortwave cloud radiative cooling is even larger than in the $T$ model, probably as a result of the different cloud cover decrease in the warmer climate, which in the $S$ model is $1.5 \%$ smaller than in the $T$ model (Table 3 , column 8 ). The most remarkable difference between the $T$ model and the $S$ model is the changed sign of $\triangle \mathrm{LCF}$ which is large and positive in the $S$ model, so that even the net cloud feedback is positive. The large $\triangle \mathrm{LCF}$ has to be related to the substantial increase of the total cloud water content in the warmer atmosphere by about $20 \%$ (cf. Table 2 ), which is particularly relevant for nonblack cirrus clouds, so that the cirrus emissivity in the tropical upper troposphere increases actually by more than $25 \%$ (cf. Figure $6 \mathrm{c}$ ). The positive correlation between temperature and cloud water content is supported by observations [Feigelson, 1978; Heymsfield, 1993], thermodynamic theory [Betts and Harshvardhan, 1987; Platt and Harshvardhan, 1988], and previous GCM studies [Roeckner et al., 1987; Mitchell et al., 1989; Le Treut and Li, 1991; Taylor and Ghan, 1992; Senior and Mitchell, 1993]. These studies also indicate that the percentage change of cloud water with temperature is a function of the temperature itself, and the largest change is to be expected for cold high-level cirrus clouds. The liquid water content in warm low-level clouds, on the other hand, is less sensitive to temperature changes, and International Satellite Cloud Climatology Project measurements even indicate a negative correlation between temperature and cloud optical depth for warm continental clouds and almost all maritime clouds [Tselioudis et al., 1992]. One has to note, however, that the optical properties of clouds in the real atmosphere are not only a function of the total cloud water content but depend 
Table 3. Global Mean Sensitivity Parameters $\left(\mathrm{K} /\left(\mathrm{W} \mathrm{m} \mathrm{m}^{-2}\right)\right.$ for the Total AtmosphereSurface System, Including Cloud Effects $(\lambda)$, and for Clear-Sky Reference Atmosphere $\left(\lambda_{c s}\right)$

\begin{tabular}{lccccrrr}
\hline \multicolumn{1}{c}{ Model } & $\lambda_{c s}$ & $\lambda$ & $\lambda / \lambda_{c s}$ & $\Delta$ CF & $\Delta$ SCF & $\Delta$ LCF & $\Delta$ CC \\
\hline TP2-TM2 & 0.50 & 0.40 & 0.79 & -2.17 & -1.65 & -0.52 & -2.69 \\
SP2-SM2 & 0.47 & 0.56 & 1.18 & 1.32 & -1.93 & 3.25 & -1.19 \\
BP2-BM2 & 0.50 & 0.61 & 1.21 & 1.27 & 0.35 & 0.91 & -2.01 \\
Cess et al. $[1990]$ & & & & & & & \\
GCM mean & 0.47 & 0.65 & 1.38 & 1.6 & 2.1 & -0.5 & -2.1 \\
Minimum & 0.40 & 0.39 & 0.70 & -2.9 & -5.9 & -4.2 & -4.4 \\
Maximum & 0.57 & 1.23 & 2.47 & 5.1 & 7.4 & 3.0 & -0.2 \\
\hline
\end{tabular}

The $\lambda / \lambda_{c s}$ and $\Delta C F\left(W / \mathrm{m}^{2}\right)$ are measures of cloud feedback. $\Delta \mathrm{SCF}$ and $\Delta \mathrm{LCF}$ denote the shortwave and longwave components of $\Delta \mathrm{CF}$, and $\Delta \mathrm{CC}$ is the change of total cloud cover (\%). The respective parameters obtained in a GCM intercomparison study by Cess et al. [1990] are shown in addition.

also on microphysical parameters such as droplet concentration, size spectrum or shape, and orientation of the ice crystals. Analyses of ground-based lidar/radiometer and in situ aircraft measurements of cloud properties [Platt, 1989] suggest that the cirrus emissivity is actually less sensitive to a change of temperature than the cloud water content, because the particle mode radius is positively correlated with temperature as well. To summarize, the theoretical and observational analyses mentioned above indicate that the temperature dependence of cloud water is adequately captured by those GCMs which simulate the cloud water content on the basis of a prognostic equation. The radiative impact, however, is probably overestimated because the temperature dependence of cloud microphysical parameters is presently not considered in GCMs.

In the black cirrus case (B model), the cloud-induced increase of climate sensitivity is nearly the same as in the $S$ model. The contributions from $\triangle \mathrm{SCF}$ and $\triangle \mathrm{LCF}$ are different, however. Since a change of cirrus emissivity is excluded by the experimental design, analogous to the $T$ model, the positive LCF response is caused by a cloud water increase in semitransparent tropical midlevel clouds which are much more abundant in the $B$ model than in the $T$ model. The change from a large negative SCF response in the $S$ model to a positive one in the $B$ model cannot be understood from the change of global mean climate variables alone. We can only conclude that the positive SCF response resulting from the $2 \%$ decrease of total cloud cover is larger than the negative contribution due to the increased cloud optical depth.

A more detailed feedback analysis with the aid of the model's radiation code [Wetherald and Manabe, 1980; Roeckner et al., 1987] or using an energy balance model [Schlesinger, 1986] is beyond the scope of this paper. Nevertheless, this simple analysis already indicates a potentially crucial role of cirrus clouds in regulating the sensitivity of the real climate system. In particular, this study shows that the cloud optical depth feedback [Somenville and Remer, 1984] is possibly large and should be included in climate models, although its net effect is still under discussion [Schlesinger and Roeckner, 1988; Platt, 1989; Mitchell et al., 1989; Le Treut and Li, 1991; Taylor and Ghan, 1992; Senior and Mitchell, 1993].

\section{Summary and Conclusions}

Two main objectives have been addressed in this paper, namely, the impact of high-level cirrus clouds and global SST warming on the climate of the ECHAM model, with emphasis on the tropics, and the dependence of global climate sensitivity on the cirrus cloud radiative properties in the reference climate. As a prerequisite for the sensitivity study, we investigate the skill of the model in simulating the observed distribution of the cloud radiative forcing as analyzed from ERBE data. It is shown that the model realistically reproduces the observed large-scale features, such as the annual cycle and the response to observed interannual SST variations in the equatorial Pacific.

Despite the fact that the SST is prescribed in the experiments and hence cannot respond to a changed model parameter, the radiative impact of changed cirrus cloud emissivity on the atmospheric temperature distribution is substantial. In a sensitivity experiment where all "cirrus" clouds (i.e., all clouds above the $400-\mathrm{hPa}$ level) are assumed transparent in the infrared, the whole troposphere cools by several degrees with maxima of $8 \mathrm{~K}$ at about $600 \mathrm{hPa}$ over the summer pole and $6 \mathrm{~K}$ below the tropical tropopause. The whole stratosphere, on the other hand, is warmed by several degrees. Moreover, the subtropical jet on the winter hemisphere is weakened and the mass transport of the Hadley cell is decreased. These results are broadly similar to those obtained by Slingo and Slingo [1988], Randall et al. [1989], and Sherwood et al. [1994].

If, in the other extreme, all cirrus clouds are treated as blackbodies, the temperature changes in the opposite sense. The whole troposphere warms by several degrees with a maximum of more than $10 \mathrm{~K}$ below the tropical tropopause, and the stratosphere cools by up to $16 \mathrm{~K}$. The subtropical jet on the winter hemisphere increases, while the Hadley cell is slightly weaker than in the reference experiment but poleward expanded. Most of these changes are identified also in a global warming experiment with the SST increased by $4 \mathrm{~K}$. Again, the largest warming is simulated in the tropical upper troposphere (more than $8 \mathrm{~K}$ ), the stratosphere is cooled by several degrees (although less than in the black cirrus experiment), the subtropical jet on the winter hemisphere is increased, and the Hadley cell is slightly weaker but poleward expanded as in the black cirrus experiment. The apparent similarity of both responses is partly related to the fact that the cirrus emissivity is enhanced also in the global warming experiment with the largest increase of more than $25 \%$ in the tropical upper troposphere and in the lower troposphere over Antarctica.

Even more consistent is the response of the Walker circulation and the Asian summer monsoon. Although in convectively disturbed tropical regions, the radiative heating through cirrus clouds is nearly an order of magnitude smaller than the latent heat release, it has a significant impact on the convective activity and the large-scale dynamics. If its relatively small 
direct contribution to the total diabatic heating is removed, as in the transparent cirrus experiment, the total diabatic heating in the convectively active regions, such as the West Pacific warm pool or the Indian subcontinent, is reduced by a much larger amount, the adiabatic cooling is reduced to about $50 \%$ of its value in the reference experiment, and the divergent part of the Walker circulation is about $50 \%$ weaker than in the reference experiment.

On the other hand, the Walker circulation is increased by roughly $50 \%$ relative to the reference experiment when cirrus clouds are treated as blackbodies, and a reverse Walker cell forms in the upper troposphere and lower stratosphere. The fuel for the enhanced convection in the disturbed regions is provided by additional moisture convergence through the enhanced Hadley and Walker circulations, while the evaporation over the tropical oceans actually decreases with increasing cirrus emissivity as a result of the warmer and moister boundary layer. The longwave radiative forcing generated by cirrus clouds has a substantial effect also on the tropical precipitation pattern being relatively widespread in the transparent cirrus case and more concentrated over the area of warmest SST in the other extreme when cirrus clouds are treated as blackbodies.

These results support conclusions from previous studies [Slingo and Slingo, 1988; Randall et al., 1989; Sherwood et al., 1994] that the thermodynamically direct tropical circulation systems such as the Hadley and Walker circulations or the monsoons are maintained through a positive feedback loop involving cloud radiative heating, latent heat release in convective clouds, and moisture supply by the large-scale dynamics. Since these models use different parameterizations for radiation, cloud formation, cumulus transport, and turbulent transfer, it seems fair to conclude that the respective closure assumptions do not play a decisive role in generating these interactions.

Although the thermodynamic response to global warming in the tropics is in many aspects similar to that of increasing cirrus emissivity, such as the spin-up of the Walker circulation together with more pronounced zonal asymmetries in the distribution of water vapor and clouds, the mechanisms causing these responses are not identical. In the cirrus response experiments the increase of cirrus emissivity generates a differential heat source as a result of a selection process which favors cloud radiative forcing primarily in those areas where clouds are abundant, as in the West Pacific warm pool, for example. In the global warming experiment, on the other hand, the primary heat source is latent heat release as a result of additional evaporation from the warmer ocean surface. Analogous to the cirrus experiments, the extra water vapor is not condensed locally but converging in convectively active regions with largescale lifting where the additional release of latent heat contributes to the differential heating which drives the Hadley and Walker circulations. Additionally, as in the cirrus response experiments, the increase of cloud water and ice and hence cirrus emissivity contributes to a further enhancement of the total differential heating. In conclusion, the spin-up of the Walker circulation in both the global warming and the increased cirrus emissivity experiments is a result of a selection process which enhances the diabatic heat source through asymmetries of the circulation itself, and this extra differential heating feeds back positively on the circulation, as mentioned above. All of the results discussed in this study have been obtained with an atmospheric GCM. If the feedbacks analyzed above would be relevant also for a coupled atmosphere-ocean model or the real climate system, a $\mathrm{CO}_{2}$-induced warming, for example, would initiate a sequence of events which could have an impact on ENSO dynamics through an increase of the equatorial surface currents in the Pacific Ocean.

Finally, three sets of global warming experiments with different cirrus emissivities indicate that cirrus clouds are likely to play a crucial role in regulating global climate sensitivity. In the climate change experiment with the standard model, the climate sensitivity is $20 \%$ higher than in a clear-sky reference atmosphere because the increased water content in cirrus clouds in the warmer atmosphere contributes substantially to the overall positive cloud feedback. In the transparent cirrus model the cloud feedback is negative, and the global sensitivity is reduced by $20 \%$, as compared to a clear-sky reference atmosphere. Theoretical and observational analyses [Betts and Harshvardhan, 1987; Platt and Harshvardhan, 1988; Platt, 1989] suggest that the model-simulated cloud water increase in cirrus clouds is realistic. On the other hand, the model does not include a temperature dependence of the particle mode radius which is likely to reduce the radiative impact of cirrus in a warmer atmosphere [Platt, 1989]. Hence more work has to be done to improve the parameterizations of cloud microphysical and optical properties in GCMs.

\section{References}

Barnett, T. P., M. Latif, E. Kirk, and E. Roeckner, On ENSO physics, J. Clim., 4, 487-515, 1991.

Betts, A. K, and Harshvardhan, Thermodynamic constraint on the cloud liquid water feedback in climate models, J. Geophys. Res., 92, 8483-8485, 1987.

Brinkop, S., Inclusion of cloud processes in the ECHAM PBL parameterization, in Studying Climate With the ECHAM Atmospheric Model, edited by R. Sausen, Meteorol. Inst. der Univ. Hamburg, Hamburg, Germany, 1991.

Cess, R. D., and G. G. Potter, Exploratory studies of cloud radiative forcing with a general circulation model, Tellus, 39A, 460-473, 1987.

Cess, R. D., et al., Intercomparison and interpretation of climate feedback processes in 19 atmospheric general circulation models, $J$. Geophys. Res., 95, 16,601-16,615, 1990.

Cess, R. D., E. F. Harrison, P. Minnis, B. R. Barkstrom, V. Ramanathan, and T. Y. Kwon, Interpretation of seasonal cloud-climate interactions using Earth Radiation Budget Experiment data, J. Geophys. Res., 97, 7613-7617, 1992.

Dümenil, L., and E. Todini, A rainfall-runoff scheme for use in the Hamburg climate model, in Advances in Theoretical Hydrology, A Tribute to James Dooge, edited by J. P. O'Kane, Eur. Geophys. Soc. Ser. Hydrol. Sci., vol. 1, pp. 129-157, Elsevier, New York, 1992.

Feigelson, E. M., Preliminary radiation model of a cloudy atmosphere, 1, Structure of clouds and solar radiation, Beitr. Phys. Atmos., 51, 203-229, 1978.

Fu, R., A. D. Del Genio, and W. B. Rossow, Behavior of deep convective clouds in the tropical Pacific deduced from ISCCP radiances, J. Clim., 3, 1129-1152, 1990.

Gage, K. S., J. R. McAfee, D. A. Carter, W. L. Ecklund, A. C. Riddle, G. C. Reid, and B. B. Balsley, Long-term mean vertical motion over the tropical Pacific: Wind-profiling Doppler radar measurements, Science, 254, 1771-1773, 1991.

Gates, W. L., AMIP: The atmospheric model intercomparison project, Bull. Am. Meteorol. Soc., 73, 1962-1970, 1992.

Graham, N. E., and T. P. Barnett, Sea surface temperature, surface wind divergence, and convection over tropical oceans, Science, 238, 657-659, 1987.

Harshvardhan, D. A. Randall, T. G. Corsetti, and D. A. Dazlich, Earth radiation budget and cloudiness simulations with a general circulation model, J. Atmos. Sci., 46, 1922-1942, 1989.

Hartmann, D., Radiative effects of clouds on Earth's climate, in Aerosol-Cloud-Climate Interactions, edited by P. V. Hobbs, pp. 151-173, Academic, San Diego, Calif., 1993.

Hense, A., M. Kerschgens, and E. Raschke, An economical method for computing radiative transfer in circulation models, $Q . J . R$. Meteorol. Soc., 108, 231-252, 1982. 
Heymsfield, A. J., Microphysical structures of stratiform and cirrus clouds, in Aerosol-Cloud-Climate Interactions, edited by P. V. Hobbs, pp. 97-121, Int. Geophys. Ser., vol. 54, Academic, San Diego, Calif., 1993.

International Panel on Climate Change (IPCC), Scientific assessment of climate change, in WMO/UNEP, Intergovernmental Panel on Climate Change, edited by J. T. Houghton, G. J. Jenkins, and J. J. Ephraums, 365 pp., Cambridge Univ. Press, New York, 1990.

Kiehl, J. T., On the observed near cancellation between longwave and shortwave cloud forcing in tropical regions, J. Clim., 7, 559-565, 1994.

Kiehl, J. T., and V. Ramanathan, Comparison of cloud forcing derived from the Earth Radiation Budget Experiment with that simulated by the NCAR community climate model, J. Geophys. Res., 95, 11,679 $11,698,1990$.

Lau, M.-C., Modeling the seasonal dependence of the atmospheric response to observed El Nino in 1962-76, Mon. Weather Rev., 113, 1970-1996, 1985.

Le Treut, H., and Z.-X. Li, Sensitivity of an atmospheric general circulation model to prescribed SST changes: Feedback effects associated with the simulation of cloud optical properties, Clim. Dyn., $5,175-187,1991$.

Lindzen, R., and S. Nigam, On the role of sea surface temperature gradients and forcing, low level winds, and convergence in the tropics, J. Atmos. Sci., 44, 2418-2436, 1987.

Louis, J. F., A parametric model of vertical eddy fluxes in the atmosphere, Boundary Layer Meteorol., 17, 187-202, 1979.

Matveev, L. T., Cloud dynamics, in Atmospheric Sciences Library, 340 pp., D. Reidel, Norwell, Mass., 1984.

Mitchell, J.F.B., and W. J. Ingram, Carbon dioxide and climate: Mechanisms of changes in cloud, J. Clim., 5, 5-21, 1992.

Mitchell, J.F.B., C. A. Senior, and W. J. Ingram, $\mathrm{CO}_{2}$ and climate: $\mathrm{A}$ missing feedback?, Nature, 341, 132-134, 1989.

Peterson, T. C., T. P. Barnett, E. Roeckner, and T. H. Vonder Haar, An analysis of the relationship between cloud anomalies and sea surface temperature anomalies in a global circulation model, J. Geophys. Res., 97, 20,497-20,506, 1992.

Platt, C.M.R., The role of cloud microphysics in high-cloud feedback effects on climate change, Nature, 341, 428-429, 1989.

Platt, C.M.R., and Harshvardhan, The temperature dependence of cirrus extinction: Implications for climate feedback, J. Geophys. Res., 93, 11,051-11,058, 1988.

Ramanathan, V., and W. Collins, Thermodynamic regulation of ocean warming by cirrus clouds deduced from the $1987 \mathrm{El} \mathrm{Nino,} \mathrm{Nature,}$ 351, 27-32, 1991.

Ramanathan, V., E. J. Pitcher, R. C. Malone, and M. L. Blackmon, The response of a spectral general circulation model to refinements in radiative processes, J. Atmos. Sci., 40, 605-630, 1983.

Ramanathan, V., R. D. Cess, E. F. Harrison, P. Minnis, B. R. Barkstrom, E. Ahmad, and D. Hartmann, Cloud-radiative forcing and climate: Results from the Earth Radiation Budget Experiment, Science, 243, 57-63, 1989.

Randall, D. A., Harshvardhan, D. A. Dazlich, and T. G. Corsetti, Interactions among radiation, convection and large-scale dynamics in a general circulation model, J. Atmos. Sci., 46, 1943-1970, 1989.

Rasch, P. J., and D. L. Williamson, Computational aspects of moisture transport in global models of the atmosphere, Q.J. R. Meteorol. Soc., $116,1071-1090,1990$
Rasmussen, E. M., Observational aspects of ENSO cycle teleconnections, in Teleconnections Linking Worldwide Climate Anomalies, edited by M. H. Glantz, R. W. Katz, and N. Nicholls, pp. 309-343, Cambridge Univ. Press, New York, 1991.

Roeckner, E., U. Schlese, J. Biercamp, and P. Löwe, Cloud optical depth feedbacks and climate modelling, Nature, 329, 138-140, 1987.

Roeckner, E., M. Rieland, and E. Keup, Modelling of cloud and radiation in the ECHAM model, ECMWF/WCRP Workshop on Clouds, Radiative Transfer and the Hydrological Cycle, Nov. 12-15, 1990, pp. 199-222, Eur. Cent. for Medium Range Weather Forecasts, Reading, England, 1991.

Roeckner, E., et al., Simulation of the present-day climate with the ECHAM model: Impact of model physics and resolution, Max Planck Inst. Meteorol. Rep. 93, 171 pp., Hamburg, Germany, 1992.

Schlesinger, M. E., Equilibrium and transient climatic warming induced by increased atmospheric $\mathrm{CO}_{2}$, Clim. Dyn., 1, 35-51, 1986.

Schlesinger, M. E., and E. Roeckner, Negative or positive cloud optical depth feedback?, Nature, 335, 303-304, 1988.

Senior, C. A., and J.F.B. Mitchell, Carbon dioxide and climate: The impact of cloud parameterization, J. Clim., 6, 393-418, 1993.

Sherwood, S. C., V. Ramanathan, T. P. Barnett, M. K. Tyree, and E. Roeckner, Response of an atmospheric general circulation model to radiative forcing of tropical clouds, J. Geophys. Res., 99, 20,82920,845, 1994.

Slingo, A., and J. M. Slingo, The response of a general circulation model to cloud longwave radiative forcing, I, Introduction and initial experiments, Q. J. R. Meteorol. Soc., 114, 1027-1062, 1988.

Somerville, R.C.J., and L. A. Remer, Cloud optical thickness feedbacks in the $\mathrm{CO}_{2}$ climate problem, J. Geophys. Res., 89, 9668-9672, 1984.

Stephens, G. L., Radiation profiles in extended water clouds, 2, Parameterization schemes, J. Atmos. Sci., 35, 2123-2132, 1978.

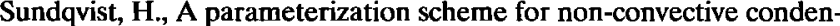
sation including prediction of cloud water content, $Q . J . R$. Meteorol. Soc., 104, 677-690, 1978.

Taylor, K. E., and S. J. Ghan, An analysis of cloud liquid water feedback and global climate sensitivity in a general circulation model, $J$. Clim., 5, 907-919, 1992.

Tiedtke, M., A comprehensive mass flux scheme for cumulus parameterization in large-scale models, Mon. Weather Rev., 117, 1779$1800,1989$.

Tselioudis, G., W. Rossow, and D. Rind, Global patterns of cloud optical thickness variation with temperature, J. Clim., 5, 1484-1495, 1992.

Wallace, J. M., Effect of deep convection on the regulation of sea surface temperature, Nature, 357, 230-231, 1992.

Wetherald, R. T., and S. Manabe, Cloud cover and climate sensitivity, J. Atmos. Sci., 37, 1485-1510, 1980.

$\mathrm{Xu}, \mathrm{K} . \mathbf{M}$., and S. K. Kruger, Evaluation of cloudiness parameterizations using a cumulus ensemble model, Mon. Weather Rev., 119 342-367, 1991.

U. Lohmann and E. Roeckner, Max-Planck-Institut für Meteorologie, Bundesstrasse 55, D-20146, Hamburg, Germany.

(Received February 15, 1994; revised March 23, 1995; accepted April 7, 1995.) 